\title{
A survey and a molecular dynamics study on the (central) hydrophobic region of prion proteins
}

\author{
Jiapu Zhang ${ }^{\text {ab* }}$, Feng Wang ${ }^{\mathrm{a}}$ \\ ${ }^{a}$ Molecular Model Discovery Laboratory, Department of Chemistry \& Biotechnology, Faculty of Science, \\ Engineering \& Technology, Swinburne University of Technology, \\ Hawthorn Campus, Hawthorn, Victoria 3122, Australia; \\ ${ }^{b}$ Graduate School of Sciences, Information Technology and Engineering, \& Centre of Informatics and \\ Applied Optimization, Faulty of Science, The Federation University of Australia, \\ Mount Helen Campus, Ballarat, Victoria 3353, Australia; \\ *Email: jiapuzhang@swin.edu.au,j.zhang@federation.edu.au,jiapu_zhang@hotmail.com \\ Tel: +61-3-9214 5596, +61-3-5327 6335, +61-423487360
}

\begin{abstract}
Prion diseases are invariably fatal neurodegenerative diseases that affect humans and animals. Unlike most other amyloid forming neurodegenerative diseases, these can be highly infectious. Prion diseases occur in a variety of species. They include the fatal human neurodegenerative diseases Creutzfeldt-Jakob Disease (CJD), Fatal Familial Insomnia (FFI), Gerstmann-Strussler-Scheinker syndrome (GSS), Kuru, the bovine spongiform encephalopathy (BSE or 'mad-cow' disease) in cattle, the chronic wasting disease (CWD) in deer and elk, and scrapie in sheep and goats, etc. Transmission across the species barrier to humans, especially in the case of BSE in Europe, CWD in North America, and variant CJDs (vCJDs) in young people of UK, is a major public health concern. Fortunately, scientists reported that the hydrophobic region of prion proteins (PrP) controls the formation of diseased prions. This article gives a detailed survey on PrP hydrophobic region and does molecular dynamics studies of human $\operatorname{PrP}(110-136)$ to confirm some findings from the survey.
\end{abstract}

Keywords: prion diseases; prion protein; central hydrophobic region; a detailed survey; molecular dynamics study

\section{Introduction}

"Mad cow disease" (i.e. Bovine Spongiform Encephalopathy (BSE)) belongs to a contagious type of Transmissible Spongiform Encephalopathies (TSEs). Scientists believe it is caused by Prions (the misfolding prion proteins) but they may have not yet solved the riddle of "mad cow disease". This is due to a prion is neither a virus, a bacteria nor any microorganism so the disease cannot be caused by the vigilance of the organism immune system and it can freely spread from one species to another species. The humans exists the susceptibility of TSEs; for example, the human version of mad cow disease named Creutzfeldt-Jakob Disease (CJD) and variant CJD (vCJD) just happen randomly through infections of transplanted tissue or blood transfusions or consumption of infected beef products. Cat, mink, deer, elk, moose, sheep, goat, nyala, oryx, greater kudu, ostrich and many other species are also susceptible to TSEs. Scientists do not know the reason of TSEs. 
Fortunately, scientists reported that the hydrophobic region 109-136 of prion proteins (PrP) controls the formation of diseased prions. This article firstly gives a detailed survey on PrP hydrophobic region; secondly, this article does molecular dynamics (MD) studies of human PrP(110-136) (PDB ID: 2LBG.pdb) to confirm some findings from the survey and to try to reveal something new.

It was reported that the hydrophobic region $\operatorname{PrP}(109-136)$ controls the formation of diseased prions: the normal $\operatorname{PrP}(113-120)$ AGAAAAGA palindrome is an inhibitor/blocker of prion diseases [Brown (2000); Holscher et al. (1998)] and the highly conserved glycine-xxx-glycine motif $\operatorname{PrP}(119-131)$ can inhibit the formation of infectious prion proteins in cells [Harrison et al. (2010); Cheng et al. (2011); Lee et al. (2008)]. The first part of this article will review the research works on all the PrP hydrophobic regions.

The infectious diseased prion is thought to be an abnormally folded isoform $\left(\mathrm{PrP}^{\mathrm{Sc}}\right)$ of a host protein known as the prion protein $\left(\mathrm{PrP}^{\mathrm{C}}\right)$. The conversion of $\mathrm{PrP}^{\mathrm{C}}$ to $\mathrm{PrP}^{\mathrm{Sc}}$ occurs post-translationally and involves conformational change from a predominantly $\alpha$-helical protein to one rich in $\beta$-sheet amyloid fibrils. Much remains to be understood about how the normal cellular isoform of the prion protein $\operatorname{PrP}^{\mathrm{C}}$ undergoes structural changes to become the disease associated amyloid fibril form $\operatorname{PrP}^{\mathrm{Sc}}$. Such a structural conformational change may be amenable to study by MD techniques. The second part of this article will do MD studies on the hydrophobic region 110-136 of human PrP (HuPrP).

The rest of this paper is organized as follows. Firstly, we will review previous experimental research results in the laboratories (not on the computers) on the hydrophobic region of PrP listed in the PubMed of NCBI (http://www.ncbi.nlm.nih.gov/pubmed). Secondly, we will present MD simulation studies on $\operatorname{HuPrP}(110-136)$. Lastly, concluding remarks on PrP hydrophobic region are summarized.

\section{A detailed review on PrP hydrophobic region}

The highly and evolutionarily conserved PrP hydrophobic region has been considered essential to PrP conformational conversion. This section does a survey of the research work on prion hydrophobic region listed in the PubMed database mainly from the molecular structure point of view.

- 2014:

- Chu et al. (2014) equipped $\Delta 105-125, \Delta$ CR_PrP (i.e. the PrP missing central hydrophobic region, a variant that is known to be highly neurotoxic in transgenic mice) with a C-terminal membrane anchor via a semisynthesis strategy and found the importance of the central hydrophobic domain in the membrane anchor in PrP-lipid interactions [Chu et al. (2014)].

- Daskalov et al. (2014) studied the HET-s prion (which owns a $\beta$-solenoid with a triangular hydrophobic core) and identified a region that modulates prion formation [Daskalov et al. (2014); Saupe (2011)]. Solid-state NMR data showed the hydrophobic core of HET-s(218-289) is rigid [Lange et al. (2009)]. 
- Xu et al. (2014) presented the structures of prion-like MAVS and found there are "electrostatic interactions between neighboring strands and hydrophobic interactions within each strand" [Xu et al. (2014)].

- Baral et al. (2014) did promazine binding to mouse PrP and found the "binding induces structural rearrangement of the unstructured region proximal to $\beta 1$, through the formation of a "hydrophobic anchor" and promazine "stabilizes the misfolding initiator-motifs such as the $\mathrm{C}$ terminus of $\alpha 2$, the $\alpha 2-\alpha 3$ loop, as well as the polymorphic $\beta 2-\alpha 2$ loop" Baral et al. (2014)].

- Coleman et al. (2014) studied the murine homologues (G113V and A116V, which lie in the hydrophobic domain of PrP) and concluded that "the hydrophobic domain is an important determinant of PrP conversion" |Coleman et al. (2014); Zhang (2014a)].

- Mays et al. (2014) studied the C1 cleavage that occurs amino-terminal of $\mathrm{PrP}^{\mathrm{C}}$ 's hydrophobic domain [Mays et al. (2014)].

- 2013:

- Wang et al. (2013) used [Au(bpy) $\left.\mathrm{Cl}_{2}\right] \mathrm{PF}_{6}$ and $\left[\mathrm{Au}(\right.$ dien) $\mathrm{Cl}] \mathrm{Cl}_{2}$ (where bpy is 2,2'-bipyridine and dien is diethylenetriamine), six prion peptides with either a His111-mutated or a Met109/112-mutated residue to investigate interaction and peptide aggregation [Wang et al. (2013)].

- Pimenta et al. (2013) described the NMR structure of ovine prion-like Doppel peptide (1-30) (PDB ID: 2M1J) and the interaction of this peptide with the conserved SRP54M hydrophobic groove [Pimenta et al. (2013)].

- The central domain (CD, 95-133) of $\mathrm{PrP}^{\mathrm{C}}$ comprises the charge cluster (CC, 95-110) and a hydrophobic region (HR, 112-133); Vilches et al. (2013) reported that among $\mathrm{CC}, \mathrm{HR}$ and $\mathrm{CD}$ only the $\mathrm{CD}$ peptide is neurotoxic and this peptide is able to activate caspase- 3 and disrupt the cell membrane, leading to cell death [Vilches et al. (2013)].

- "Among mutants spanning the region 95-135, a construct lacking solely residues 105-125 $(\triangle 105-125)$ had distinct properties when compared with the full-length prion protein 23-231 or other deletions" [Patel et al. (2013)].

- Zweckstetter (2013) reported that "prion stop mutants that accumulate in amyloidogenic plaque-forming aggregates fold into a $\beta$-helix" and residue 129 is located in the hydrophobic core of the $\beta$-helix, the trimer interface of a trimeric left-handed $\beta$-helix model is formed by residues L125, Y128 and L130 [Zweckstetter (2013)].

- 2012 :

- Lau et al. (2012) demonstrated that Shadoo (Sho) binds DNA and RNA in vitro via the arginine-rich (or alanine-rich) hydrophobic region of five tandem A/LAAG amino residue repeats R1-R5 (including tandem positively charged "RGG boxes"), where is the most homologous region of Sho and $\operatorname{PrP}$ (but Sho sequences showed variability in the number of alanine residues) LLau et al. (2012); Daude et al. (2010); Stewart et al. (2009)].

- Zhao et al. (2012) reported that "two fixed missense mutations (102Ser $\rightarrow$ Gly and $119 \mathrm{Thr} \rightarrow \mathrm{Ala}$ ), and three missense mutations $(92 \mathrm{Pro}>\mathrm{Thr} / \mathrm{Met}, 122 \mathrm{Thr}>\mathrm{Ile}$ 
and 139Arg $>$ Trp $)$ in the coding region presenting different $(\mathrm{P}<0.05)$ genotypic and allelic frequency distributions between cattle and buffalo" [Zhao et al. (2012)].

- 14-3-3 beta protein (highly abundant in brain, a biomarker for SCJD) interacts with the central hydrophobic amino acids 106-126 of prion protein [Jeong et al. (2012)].

- The $\alpha$-cleavage within the central hydrophobic domain not only disrupts a region critical for both $\mathrm{PrP}$ toxicity and $\mathrm{PrP}^{\mathrm{C}}$ to $\mathrm{PrP}^{\mathrm{Sc}}$ conversion but also produces the $\mathrm{N} 1$ fragment that is neuroprotective and the $\mathrm{C} 1$ fragment that enhances the proapoptotic effect of staurosporine in one report and inhibits prion in another [Liang et al. (2012)].

- Zhang et al. (2012) found a new haplotype in a Sunite sheep and the sheep of Inner Mongolia in China have several haplotypes with the similar results of Stewart and Daude's: SPRN (shadowof prion protein homology) contained an alanine-rich sequence, which is homologous to a hydrophobic core with amyloidgenic characteristics in PrP [Zhang et al. (2012)].

- Sauve et al. (2012) published the NMR structure of HuPrP(110-136) in dodecylphosphocholine (DPC) micelles (PDB ID: 2LBG) [Sauve et al. (2012)].

- 2011:

- Biljan et al. (2011) published the NMR structure of HuPrP-M129 mutant V210I (85-231) (PDB ID: 2LEJ) including the unstructured N-terminal part (residues 90-124) [Biljan et al. (2011)].

- Julien et al. (2011) reported the relative and regional stabilities of the hamster, mouse, rabbit, and bovine PrPs towards urea unfolding, and also investigated the effect of the S174N mutation in rabbit $\operatorname{PrP}^{\mathrm{C}}$ [Julien et al. (2011)].

- Shi et al. (2011) reported that point-mutations within the hydrophobic transmembrane region increase the amount of ${ }^{\mathrm{Ctm}} \operatorname{PrP}\left(\right.$ a kind of $\left.\operatorname{PrP}^{S c}\right)$ in cells, such as human homologue A117V which is associated with GSS and G114V associated with gCJD, while the mutations outsides transmembrane region do not [Shi et al. (2011)].

- 2010

- Wang et al. (2010) reported that "the hydrophobic domain deletion mutant significantly weakened the hydrophobic rPrP-lipid interaction and abolished the lipid-induced C-terminal PK-resistance", "both disease-associated P105L and P102L mutations, localized between lysine residues in the positively charged region, significantly affected lipid-induced rPrP conversion" and "the hydrophobic domain localized 129 polymorphism altered the strength of hydrophobic $\operatorname{rPrP}($ recombinant mouse PrP)-lipid interaction" Wang et al. (2010)].

- Ile et al. (2010) published the NMR structure of HuPrP-M129 mutant Q212P (PrP(90-231)) (PDB ID: 2KUN) and concluded that the Q212P mutation caused GSS syndrome might be due to the disruptions of the hydrophobic core consisting of $\beta 2-\alpha 2$ loop and $\alpha 3$ helix [Ile et al. (2010)]. 
- Biasini et al. (2010) revealed through the deleting residues 114-121 ( $\triangle 114$ $121)$ that the hydrophobic core region governs mutant prion protein aggregation and intracellular retention [Biasini et al. (2010)].

- Harrison et al. (2010) reported that there are similarities between $\mathrm{A} \beta$ (Alzheimer's amyloid- $\beta$ ) and PrP in the segment of the three GxxxG repeats (where both $\mathrm{A} \beta$ and $\operatorname{PrP}$ have the crucial residue Methionine located in the middle $(\mathrm{GxMxG})$ of the last repeat) that controls prion formation, and found that minor alterations to this highly conserved region of $\mathrm{PrP}^{\mathrm{C}}$ drastically affect the ability of cells to uptake and replicate prion infection in both cell and animal bioassay [Harrison et al. (2010); Zhang (2014a)].

- Oliveira-Martins et al. (2010) reported that " $\mathrm{PrP}^{\mathrm{C}}$ undergoes extensive proteolysis at the $\alpha$ site $(109 \mathrm{~K} \downarrow \mathrm{H} 110)$ " and "C1 prevalence was unaffected by variations in charge $(\operatorname{PrP}(90-110))$ and hydrophobicity $(\operatorname{PrP}(110-130))$ of the region neighbouring the $\alpha$-cleavage site, and by substitutions of the residues in the palindrome that flanks this site, instead, $\alpha$-cleavage was size-dependently impaired by deletions within the domain $\operatorname{PrP}(106-119)$ )" Oliveira-Martins et al. (2010)].

- The hydrophobic core $(\mathrm{HC})$, a transmembrane domain, harbors the most highly conserved regions of $\mathrm{PrP}^{\mathrm{C}}$. A mutation in $\mathrm{HC}$ is associated with prion disease resulting in an enhanced formation of a transmembrane form ( $\left.{ }^{\mathrm{Ctm}} \mathrm{PrP}\right)$. Lutz et al. (2010) created a set of mutants carrying microdeletions of 28 amino acids within HC between position 114 and $121(\triangle 114$ 121 ), and showed that these mutations display reduced propensity for transmembrane topology and $\mathrm{HC}$ might function as recognition site for the protease(s) responsible for $\operatorname{PrP}^{\mathrm{C}} \alpha$-cleavage [Lutz et al. (2010)]. They also found that the mutant G113V displayed increased ${ }^{\mathrm{Ctm}} \mathrm{PrP}$ topology and decreased $\alpha$-cleavage in their in vitro assay and concluded that $\mathrm{HC}$ represents an essential determinant for transmembrane PrP topology, whereas the high evolutionary conservation of this region is rather based upon preservation of $\operatorname{PrP}^{\mathrm{C}} \alpha$-cleavage, thus highlighting the biological importance of this cleavage.

- Valensin et al. (2010) reported that HuPrP possesses two copper binding sites localized at His-96 and His-111 in the so called "amylodogenic" or neurotoxic region (residues 91-126) and chicken PrP possesses a similar region $(\operatorname{PrP}(105-140))$ containing two His (His-110 and His-124) and an identical hydrophobic tail of 15 amino acids rich in Ala and Gly [Valensin et al. (2010)].

- Turi et al. (2010) studied HuPrP(91-115), HuPrP(76-114)H85A and HuPrP(84114)H96A and found that His 96 predominates almost completely for nickel(II) ions, while His85 and His111 predominate copper(II) ions [Turi et al. (2010); Joszai et al. (2012); Cui et al. (2014)].

- 2009:

- Julien et al. (2009) reported that "strong hydrophobic interactions between helices $\alpha 1$ and $\alpha 3$, and between $\alpha 2$ and $\alpha 3$, stabilize these regions even at very high concentrations of urea" but this result is for PrP structural region $121-230$ of bovine [Julien et al. (2009)]. 
- Fei et al. (2009) reported Preceding with a hydrophobic residue cysteine, instead of a charged residue, "caused the rate of assembly into fibrils to increase greatly for both peptides and full-length Ure2p", and concluded that "disulfide bond formation significantly accelerates the assembly of Ure2p fibrils because of the proximity of a potential amyloid stretch" |Fei et al. (2009)].

- Tseng et al. (2009) reported that hydrophobic does not play a major role in the unfolding of $\alpha$-helix 1 of $\operatorname{PrP}^{\mathrm{C}}$ [Tseng et al. (2009)] but In the mouse PrP (PDB ID: 1AG2) there are nine hydrophobic residues and five nonpolar Glycines in $\beta 1$-strand: GLGGYMLGSAMSRPMIHFGN(PrP(124$142)$ ), five hydrophobic residues in $\beta 2$-strand: N153MYRYPNQV YYRPVD167 (PrP(153-167)).

- 2008:

- Margittai et al.(2008) found that, to maximize the hydrophobic contact surface, most fibrils (that contain an extensive core region of about 20 amino acids or more) share a common parallel in-register arrangement of $\beta$-strands [Margittai et al. [2008)].

- Ciccotosto et al. (2008) reported "the major region of neurotoxicity has been localized to the hydrophobic domain located in the middle of the PrP sequence" [Ciccotosto et al. (2008)].

- 2007:

- Owen et al. (2007) reported "the protease thermolysin cleaves at the hydrophobic residues Leu, Ile, Phe, Val, Ala, and Met, residues that are absent from the protease accessible aminoterminal region of $\operatorname{PrP}^{\mathrm{Sc}}$ " [wen et al. (2007)].

- Ott et al. (2007) reported "the presence of small hydrophobic amino acids such as Val and Ile was insufficient to promote re-orientation. Only Met and Leu, large hydrophobic amino acids, could promote transmembrane domain inversion" [Ott et al. (2007)].

- Sakudo et al. (2007) reported that neurotoxic signals of aged $\operatorname{PrP}(106-126)$ are mediated by N-terminal half of the hydrophobic region (HR) but not the octapeptide repeat (OR) of PrP [Sakudo et al. (2007)].

- Berti et al. (2007) reported the copper(II) binding result of the 91-120 region of HuPrP: "room-temperature NMR spectroscopy data were consistent with the binding site centered on His 111 being approximately fourfold stronger than that centered on His96, low-temperature EPR spectroscopy results yielded evidence for the opposite trend", and the MD results showed that "Met112 approaching the metal at room temperature, a process that is expected to stabilize the His111-centered binding site through hydrophobic shielding of the metal coordination sphere" [Berti et al. (2007)].

- Harrison et al. (2007) summarized the GxxxG PrPctm motif GAVVGGLGGYMLG and made a mutation G131V leading to the possibility that this motif may be relevant to the actions of TM-PrP [Harrison et al. (2007)].

- 2006: 
- Lee et al. (2006) found that "the OR (octapeptide repeat region, $\operatorname{PrP}(51-$ 90)) and N-terminal half of HR (hydrophobic region, PrP(112-145)) of PrP retains anti-apoptotic activity similar to full-length PrP" [Lee et al. (2006)].

- 2005

- Sakudo et al. (2005a) reported that "OR and N-terminal half of the HR were required for the inhibitory effect of $\operatorname{PrP}(113-132)$ but not STI1 (stressinducible protein 1) pep.1" and "mediate the the action of STI1 upon cell survival and upregulation of SOD (superoxide dismutase) activity" [Sakudo et al. (2005a)]. In 2005, Sakudo et al. (2005b) also reported that "Removal of the OR (PrP(53-94)) enhances apoptosis and decreases SOD activity. Deletion of the N-terminal half of HR $(\operatorname{PrP}(95-132))$ abolishes its ability to activate SOD and to prevent apoptosis, whereas that of the C-terminal half of HR $(\operatorname{PrP}(124-146))$ has little if any effect on the anti-apoptotic activity and SOD activation" [Sakudo et al. (2005b)].

- Gaggelli et al. (2005) did NMR and EPR studies on the interaction of the HuPrP(106-126) (KTNMKHMAGAAAAGAVVGGLG) with copper(II), manganese(II) and zinc(II) at pH 5.7 and concluded that "the hydrophobic C-terminal region was not affecting the copper-binding (of His111) properties of the peptide and this hydrophobic tail is left free to interact with other target molecules" Gaggelli et al. (2005)].

- 2004

- Kuznetsov et al. (2004) reported that " $\operatorname{PrP}(114-125)$ and the C terminus of helix B may be considered as primary candidates for sites involved in conformational transition from $\operatorname{PrP}^{\mathrm{C}}$ to $\mathrm{PrP}^{\mathrm{Sc}}$ " and "most $\operatorname{PrP}$ mutations associated with neurodegenerative disorders increase local hydrophobicity" [Kuznetsov et al. (2004)].

- Ott et al. (2004) reported that "the $\mathrm{N}$ terminal and hydrophobic regions of the signal sequence affect (membrane) integration (of priton protein) most significantly. Mutations in either region result in a considerable increase in the number of chains that integrate" [Ott et al. (2004)].

- Haire et al. (2004) reported that the strand of residues 129-131 in sheep PrP crystal structure is involved in lattice contacts about a crystal dyad to generate a four-stranded intermolecular $\beta$-sheet between neighbouring molecules [Haire et al. (2004)].

- 2003:

- Susceptibility to scrapie is primarily controlled by polymorphisms in the ovine PrP gene (PRNP) and Seabury et al. (2003) reported a polymorphism of ovine PrP at Proline 116, flanking the cleavage site between Lys112 and His113, and A117V (causing Gerstmann-Strausler-Scheinker syndrome) [Seabury et al. (2003)].

- Saez-Cirion et al. (2003) reported that the hydrophobic internal region 130GAVVGGLGGYMLGSAMSR147 of bovine PrP shares structural and functional properties with HIV type 1 fusion peptide [Saez-Cirion et al. (2003)]. The 121KHVAGAAAAGAVVGGLGGYMLGSAMSR147 transmembrane region (BovinePrP(tm)) has mainly a helical structure but also 
containing some random coil (upon addition of calcium, the random coils disappear while the helical conformation remains) [Saez-Cirion et al. (2003)]. Amyloid-type fibers $\mathrm{PrP}^{\mathrm{Sc}}$ will be formed, if in the absence of membrane prion sequence [Saez-Cirion et al. (2003)].

- Tcherkasskaya et al. (2003) reported that hydrophobic interactions between side chains of the peptide variants $\operatorname{PrP}(104-122)$ (containing a polar head KTNMKN followed by a long hydrophobic tail MAGAAAAAGAVV) and $\operatorname{PrP}(109-122)$ prevent the formation of the rigid $\beta$-sheet structures [Tcherkasskaya et al. (2003)].

- Premzl et al. (2003) reported that the alignment of the hydrophobic segment shows strong conservation across all PrPs and Shadoos; 12 of the 20 residues of the hydrophobic region are identical or almost identical, and another 6 are conserved hydrophobic [Premzl et al. (2003)].

- Cui et al. (2003) investigated the deletions of the hydrophobic domain $(\operatorname{PrP} \Delta(112-119), \operatorname{PrP}(112-136), \operatorname{PrP}(135-150))$ and found that the conserved hydrophobic core region is a critical domain for the activity of PrP [Cui et al. (2003)].

- Kourie et al. (2003) reported that copper modulates the ion channels of $\operatorname{PrP}[106-126]$ mutant prion peptide fragments, the hydrophobic core AGAAAAGA is not a ligand $\mathrm{Cu}(2+)$ site but the $\mathrm{Cu}(2+)$-binding site is located at $\mathrm{M}(109)$ and $\mathrm{H}(111)$ of prion fragment PrP[106-126] [Kourie et al. (2003)].

- In mouse PrP, the selected rabbit-specific mutations Asn99Gly, Leu108Met, Asn173Ser, and Val214Ile significantly interfere with the conversion of $\mathrm{PrP}^{\mathrm{C}}$ to $\mathrm{PrP}^{\mathrm{Sc}}$ [Vorberg et al. (2003)].

- 2002:

- Suzuki et al. (2002) reported that Fugu PrP-like has the PrP-conserved hydrophobic region of the Xenopus PrP (but doppel gene lacks PrP conserved hydrophobic region) [Suzuki et al. (2002)].

- The amino acid sequence AGAAAAGA, comprising residues 112-119 of the murine $\operatorname{PrP}^{\mathrm{C}}$, has been shown to be amyloidogenic and evolutionarily conserved [Zhang (2014b)]. To assess the effect of mutations at and around this hydrophobic sequence on protease resistance, Wegner et al. (2002) replaced the sequence either by alanines or by glycines and, in a third mutant, a large part surrounding this region was removed. At last Wegner et al. (2002) concluded that "mutations in the central hydrophobic region lead to immediate alterations in PrP structure and processing" Wegner et al. (2002)].

- Chen et al. (2002) reported "one O-linked sugar at Ser135 can affect the coil-to-beta structural transition of the prion peptide" but at Ser132 the effect is opposite [Chen et al. (2002)], where $\operatorname{PrP}^{\mathrm{C}}(132-140)$ domain is closely related to the prion propagation and $132-140$ portion of $\mathrm{PrP}^{\mathrm{C}}$ is a logical target for development of anti-prion drugs [Peretz et al. (2001)].

- 2001:

- Dragani et al. (2001) showed that, in the hydrophobic core of all GST (glutathione S-transferase) and related protein (including the yeast prion 
protein Ure2), at the beginning of $\alpha 6$-helix of GST domain II, a N-capping box $(\mathrm{S} / \mathrm{TxxD})$ and an hydrophobic staple motif are strictly conserved in all GSTs and GST-related proteins [Dragani et al. (2001); Khan et al. (2010); Sweeting et al. (2013)].

- Holscher et al. (2001) reported that "deletion of each of the two hydrophobic regions in $\operatorname{PrP}$ (i.e. $\Delta \operatorname{PrP}(112-121), \Delta \operatorname{PrP}(231-254))$ revealed that the C-terminally located hydrophobic region (transmembrane2, $\operatorname{PrP}(213-254)$ ) can function as second signal sequence in PrP" Holscher et al. (2001)].

- A direct correlation between the PrP amino acid sequence and TSE incubation time was demonstrated in transgenic mice expressing mouse PrP with amino acid substitutions Val111Met, Leu108Met, Pro101Leu [Supattapone et al. (2001); Barron et al. (2001, 2003)].

- Knaus et al. (2001) observed the N-terminal residues PrP(119-124) in the electron density of the crystal structure of HuPrP dimer (but the PrP(119124) region is disordered in the NMR structure of PrP monomers) (Knaus et al. (2001)].

- Laws et al. (2001) reported the solid-state NMR structure of $\operatorname{MoPrP}(89$ 143, P101L) [Laws et al. (2001)].

- 1999

- Ragg et al. (1999) obtained the two-dimensional ${ }^{1} \mathrm{H}$ NMR structure of $\operatorname{PrP}(106-126)$ under the following solvent conditions: deionized water/2,2,2trifluoroethanol 50:50 (v/v) and dimethylsulfoxide; and the data were analyzed by restrained MD calculations [Ragg et al. (1999)]. "In deionized water at $\mathrm{pH} 3.5$, the peptide adopted a helical conformation in the hydrophobic region spanning residues Met112-Leu125, with the most populated helical region corresponding to the Ala115-Ala119 segment $(\approx 10 \%)$. In trifluoroethanol/ $\mathrm{H}_{2} \mathrm{O}$, the $\alpha$-helix increased in population especially in the Gly119-Val122 tract $(\approx 25 \%)$. The conformation of this region was found to be remarkably sensitive to $\mathrm{pH}$, as the Ala120-Gly124 tract shifted to an extended conformation at $\mathrm{pH}$ 7. In dimethylsulfoxide, the hydrophobic cluster adopted a prevalently extended conformation. For all tested solvents the region spanning residues Asn108-Met112 was present in a 'turnlike' conformation and included His111, situated just before the starting point of the $\alpha$-helix. Rather than by conformational changes, the effect of His111 is exerted by changes in its hydrophobicity, triggering aggregation. The amphiphilic properties and the $\mathrm{pH}$-dependent ionizable side-chain of His111 may thus be important for the modulation of the conformational mobility and heterogeneity of $\operatorname{PrP}(106-126) "$ |Ragg et al. (1999)].

- Kanyo et al. (1999) determined the X-ray crystallographic atomic-resolution structures of Syrian hamster PrP(104-113) binding Fab 3F4 [Kanyo et al. (1999)]. "The peptide binds in a U-shaped groove on the Fab surface, with the two specificity determinants, Met109 and Met112, penetrating deeply into separate hydrophobic cavities formed by the heavy and light chain complementarity-determining regions, and two intrapeptide hydrogen bonds are observed" Kanyo et al. (1999)].

- Liu et al. (1999) reported some NMR information for the Syrian hamster $\operatorname{PrP}(90-123)$ : "the N-terminus (residues 90-119) is largely unstructured 
despite some sparse and weak medium-range NOEs implying the existence of bends or turns. The transition region between the core domain and flexible N-terminus, i.e., residues 113-128, consists of hydrophobic residues or glycines and does not adopt any regular secondary structure in aqueous solution. There are about 30 medium- and long-range NOEs within this hydrophobic cluster, so it clearly manifests structure" in 1B10.pdb [Liu et al. (1999)].

- 1997:

- Smith et al. (1997) compared CD (circular dichroism) data from two peptides corresponding to the hydrophobic region $\operatorname{PrP}(106-136)$ which contained either methionine or valine at position 129 and concluded that "there was no detectable difference between the CD spectra of these peptides irrespective of the solvent conditions we used" [Smith et al. (1997)].

- 1996:

- Inouye et al. (1996) revealed the hydrophobic core in prion by X-ray diffraction as the beta-silk structure [Inouye et al. (1996)].

- 1995:

- Priola et al. (1995) found that "a single hamster PrP amino acid Met138 blocks conversion to protease-resistant PrP in scrapie-infected mouse neuroblastoma cells" (while a mouse specific isoleucine Ile138 facilitated the conversion of mouse $\operatorname{PrP}^{\mathrm{C}}$ into $\mathrm{PrP}^{\mathrm{Sc}}$ ) [Priola et al. (1995)]. They also found homology at $\mathrm{PrP}(112-138)$ was required for mouse $\mathrm{PrP}^{\mathrm{C}} \rightarrow \mathrm{PrP}^{\mathrm{Sc}}$ conversion [Priola et al. (1995); Moore et al. (2005)].

- 1994:

- De Fea et al. (1994) reported that "a charged, extracytoplasmic region, termed the Stop Transfer Effector (STE) sequence, has been shown to direct then ascent translocating chain to stop at the adjoining hydrophobic domain to generate the first membrane-spanning hydrophobic region $\operatorname{PrP}(112-143)$ " [De Fea et al. (1994)].

- 1993:

- Harris et al. (1993) proposed that the cleavage is lying within a region of 24 amino acids that is identical in chicken PrP and mammalian PrP and is representing a major processing event that may have physiological as well as pathological significance [Harris et al. (1993)].

- 1992

- Muramoto et al. (1992) found that $\Delta \operatorname{PrP}(95-107), \Delta \operatorname{PrP}(108-121)$, and $\Delta \operatorname{PrP}(122-140)$ inhibit the $\operatorname{PrP}^{\mathrm{C}} \rightarrow \mathrm{PrP}^{\mathrm{Sc}}$ conversion [Muramoto et al. (1992)]. Kuwata et al. (2003) furthermore reduced the region of residues and found that mouse PrP(106-126) can form amyloid-like fibrils ("the fibrils contain $\approx 50 \% \beta$-sheet structure, and strong amide exchange protection is limited to the central portion of the peptide spanning the palindromic sequence VAGAAAAGAV") [Kuwata et al. (2003)]. PrP(90-140) might be the region of interactions between $\operatorname{PrP}^{\mathrm{C}}$ and $\operatorname{PrP}^{\mathrm{Sc}}$ [Viles et al. (2001)]. 
- 1987

- Liao et al. (1987) cloned and sequenced rat prion-related protein (PrP) cDNA, and showed a 23 amino acids hydrophilic region that extends to amino acid position 122 , and the numerous $G-G-G-X$ repeats, where $\mathrm{X}$ is a hydrophobic amino acid, may function in $\beta$-pleated sheet amyloid formation [Liao et al. (1987)].

- Bazan et al. (1987) analyzed the primary PrP sequence hydrophobicities to detect potential amphipathic regions and several hydrophobic segments, a proline- and glycine-rich repeat region and putative glycosylation sites are incorporated into a PrP model [Bazan et al. (1987)].

Throughout the above review on the recent research advances of PrP hydrophobic region, we noticed that hydrophobic region $\operatorname{PrP}(109-136)$ controls the formation of diseased prions $\mathrm{PrP}^{\mathrm{Sc}}$ conformationally changed from $\mathrm{PrP}^{\mathrm{C}}$. Thus, it is necessary to do MD studies of the $\operatorname{PrP}(110-136)$ hydrophobic region in the next section.

\section{MD (molecular dynamics) studies on PrP hydrophobic region 110-136}

The NMR structure of $\operatorname{HuPrP}(110-136)$ in dodecylphosphocholine micelles was known (2LBG.pdb). We did the MD simulations for this PDB template in [Zhang et al. (2013)] but we have not published any figure of our MD results. This section will illuminate our MD results and their discussions with numerous figures.

The 5 ns' MD simulations passed (1) successful optimizations of the NMR structure and its 17 mutants (G114V, A117V, G119A, G119L, G119P, A120P, G123A, G123P, G124A, L125A, G126A, G127A, G127L, M129V, G131A, G131L, G131P), (2) the longer enough equilibration phase: the PRESS, VOLUME (DENSITY) and RMSD (Figs. 1-18) were sufficiently stable, and (3) the successful production phase (Figs. 1-18). In Figs. $1-18, \mathrm{H}$ is the $\alpha$-helix, $\mathrm{B}$ is the residue in isolated $\beta$-bridge, $\mathrm{E}$ is the extended strand, $\mathrm{G}$ is the 3 -helix or $3_{10}$ helix, $\mathrm{I}$ is the $\pi$-helix, $\mathrm{T}$ is the hydrogen bonded turn, $\mathrm{S}$ is the bend, and the dashed lines denote hydrogen bonds (HBs).

We found three main HBs GLY/ALA/LEU/PRO131-SER135-ARG136, TYR128SER132 have high occupied rates in the N-terminal of PrP structural region; this shows that $\operatorname{PrP}(110-124)$ region of $\operatorname{PrP}(110-136)$ (2LBG.pdb) is very unstable. We also found that there is a salt bridge (SB) between HIS111-LYS110 with the occupied rate $100 \%$ for 13 models. Specially for the mutants G127L, M129V, G131A, and G131L, there is another SB between HIS111-136ARG linking the head and the tail of HuPrP(110 136). Seeing the snapshots of $3 \mathrm{~ns}, 4 \mathrm{~ns}$ and $5 \mathrm{~ns}$ of mutant G127L in Fig. 13, $4 \mathrm{~ns}$ and $5 \mathrm{~ns}$ of mutant M129V in Fig. 15, 3 ns, 4 ns and 5 ns of mutant G131A in Fig. 16, and 3 ns, 4 ns and 5 ns of mutant G131L in Fig. 17, we may know the SB HIS111-ARG136 makes these snapshots looking like a "hairpin". The residue HIS111 is an important residue in $\operatorname{PrP}(110-136)$. Along with the unfolding of $\alpha$-helical structure of all these 13 models, we found many hydrophobic packings (HPs) disappeared except for some fundamental ones MET134-ALA133, LEU130-129MET, VAL122-VAL121-ALA120, ALA118-ALA117-ALA116-ALA115, and ALA113-MET112 with the occupied rate $100 \%$, where ALA118-ALA117-ALA116-ALA115 are in the core of the palindrome AGAAAAGA and this might imply to us the hydrophobic core is very hard to break and this palindrome really has enormous potential to be amyloid fibrils. 


\section{Conclusion}

It was reported that PrP hydrophobic region controls the formation into diseased prions. This article firstly reviewed on the recent research advancements of PrP hydrophobic region. Secondly, this article gave explanations on the PrP hydrophobic region in view of protein three-dimensional (3D) structures and their structural dynamics by numerous figures that illuminated the variations of protein 3D structures, protein secondary structures, and the snapshots at $0 \mathrm{~ns}, 1 \mathrm{~ns}, 2 \mathrm{~ns}, 3 \mathrm{~ns}, 4 \mathrm{~ns}$ and $5 \mathrm{~ns}$ of the MD simulations. The structural bioinformatics presented in this article can be used as a reference in 3D images for laboratory experimental works to study PrP hydrophobic region.

\section{Acknowledgments}

This research has been supported by a Victorian Life Sciences Computation Initiative (VLSCI) grant numbered VR0063 on its Peak Computing Facility at the University of Melbourne, an initiative of the Victorian Government of Australia.

\section{References}

Baral PK, Swayampakula M, Rout MK, Kav NN, Spyracopoulos L, Aguzzi A, James MN (2014) Structural basis of prion inhibition by phenothiazine compounds. Structure 22(2): 291-303.

Barron RM, Thomson V, Jamieson E, Melton DW, Ironside J,Will R, Manson JC (2001) Changing a single amino acid in the $\mathrm{N}$-terminus of murine PrP alters TSE incubation time across three species barriers. EMBO J 20(18): 5070-8.

Barron RM, Thomson V, King D, Shaw J, Melton DW, Manson JC (2003) Transmission of murine scrapie to P101L transgenic mice. J Gen Virol 84(Pt 11): 3165-72.

Bazan JF, Fletterick RJ, McKinley MP, Prusiner SB (1987) Predicted secondary structure and membrane topology of the scrapie prion protein. Protein Eng 1(2): 125-35.

Berti F, Gaggelli E, Guerrini R, Janicka A, Kozlowski H, Legowska A, Miecznikowska H, Migliorini C, Pogni R, Remelli M, Rolka K, Valensin D, Valensin G (2007) Structural and dynamic characterization of copper(II) binding of the human prion protein outside the octarepeat region. Chemistry 13(7): 1991-2001.

Biasini E, Tapella L, Restelli E, Pozzoli M, Massignan T, Chiesa R (2010) The hydrophobic core region governs mutant prion protein aggregation and intracellular retention. Biochem J 430(3): 477-86.

Biljan I, Ilc G, Giachin G, Raspadori A, Zhukov I, Plavec J, Legname G (2011) Toward the molecular basis of inherited prion diseases: NMR structure of the human prion protein with V210I mutation. J Mol Biol 412(4): 660-73.

Brown DR (2000) Prion protein peptides: optimal toxicity and peptide blockade of toxicity. Mol Cell Neurosci 15(1): 66-78.

Chen PY, Lin CC, Chang YT, Lin SC, Chan S (2002) One O-linked sugar can affect the coil-tobeta structural transition of the prion peptide. Proc Natl Acad Sci USA 99(20): 12633-8.

Cheng HM, Tsai TW, Huang WY, Lee HK, Lian HY, Chou FC, Mou Y, Chan JC (2011) Steric zipper formed by hydrophobic peptide fragment of Syrian hamster prion protein. Biochem 50(32): 6815-23. 
Chu NK, Shabbir W, Bove-Fenderson E, Araman C, Lemmens-Gruber R, Harris DA, Becker CF (2014) A C-terminal membrane anchor affects the interactions of prion proteins with lipid membranes. J Biol Chem, doi: 10.1074/jbc.M114.587345.

Ciccotosto GD, Cappai R, White AR (2008) Neurotoxicity of prion peptides on cultured cerebellar neurons. Methods Mol Biol 459:83-96.

Coleman BM, Harrison CF, Guo B, Masters CL, Barnham KJ, Lawson VA, Hill AF (2014) Pathogenic mutations within the hydrophobic domain of the prion protein lead to the formation of protease-sensitive prion species with increased lethality. J Virol 88(5): 2690-703.

Cui T, Daniels M, Wong BS, Li R, Sy MS, Sassoon J, Brown DR (2003) Mapping the functional domain of the prion protein. Eur J Biochem 270(16): 3368-76.

Cui, P.X., Lian, F.L., Wang, Y., Wen, Y., Chu, W.S., Zhao, H.F., Zhang, S., Li, J., Lin, D.H., Wu, Z.Y. (2014) 3D local structure around copper site of rabbit prion-related protein: Quantitative determination by XANES spectroscopy combined with multiple-scattering calculations. Radiat Phys Chem 95: 69-72.

Daude N, Ng V, Watts JC, Genovesi S, Glaves JP, Wohlgemuth S, Schmitt-Ulms G, Young H, McLaurin J, Fraser PE, Westaway D (2010) Wild-type Shadoo proteins convert to amyloidlike forms under native conditions. J Neurochem 113(1): 92-104.

Daskalov A, Gantner M, Wlti MA, Schmidlin T, Chi CN, Wasmer C, Schtz A, Ceschin J, Clav C, Cescau S, Meier B, Riek R, Saupe SJ (2014) Contribution of specific residues of the $\beta$-solenoid fold to HET-s prion function, amyloid structure and stability. PLoS Pathog 10(6):e1004158.

De Fea KA, Nakahara DH, Calayag MC, Yost CS, Mirels LF, Prusiner SB, Lingappa VR (1994) Determinants of carboxyl-terminal domain translocation during prion protein biogenesis. $\mathrm{J}$ Biol Chem 269(24): 16810-20.

Dragani B, Cocco R, Principe DR, Paludi D, Aceto A (2001) Conformational properties of five peptides corresponding to the entire sequence of glutathione transferase domain II. Arch Biochem Biophys 389(1): 15-21.

Fei L, Perrett S (2009) Disulfide bond formation significantly accelerates the assembly of Ure2p fibrils because of the proximity of a potential amyloid stretch. J Biol Chem 284(17): 11134 41.

Gaggelli E, Bernardi F, Molteni E, Pogni R, Valensin D, Valensin G, Remelli M, Luczkowski M, Kozlowski H (2005) Interaction of the human prion $\operatorname{PrP}(106-126)$ sequence with copper(II), manganese(II), and zinc(II): NMR and EPR studies. J Am Chem Soc 127(3): 996-1006.

Haire LF, Whyte SM, Vasisht N, Gill AC, Verma C, Dodson EJ, Dodson GG, Bayley PM (2004) The crystal structure of the globular domain of sheep prion protein. J Mol Biol 336(5): 117583 .

Harris DA, Huber MT, van Dijken P, Shyng SL, Chait BT, Wang R (1993) Processing of a cellular prion protein: identification of $\mathrm{N}$ - and $\mathrm{C}$-terminal cleavage sites. Biochemistry 32(4): 1009-16.

Harrison CF, Barnham KJ, Hill AF (2007) Neurotoxic species in prion disease: a role for PrP isoforms? J Neurochem 103(5): 1709-20.

Harrison CF, Lawson VA, Coleman BM, Kim YS, Masters CL, Cappai R, Barnham KJ, Hill $\mathrm{AF}$ (2010) Conservation of a glycine-rich region in the prion protein is required for uptake of prion infectivity. J Biol Chem 285(26): 20213-23. 
Holscher C, Bach UC, Dobberstein B (2001) Prion protein contains a second endoplasmic reticulum targeting signal sequence located at its C terminus. J Biol Chem 276(16): 13388-94.

Holscher C, Delius H, Burkle A (1998) Overexpression of nonconvertible $\mathrm{PrP}^{\mathrm{C}}$ delta114-121 in scrapie-infected mouse neuroblastoma cells leads to trans-dominant inhibition of wild-type $\operatorname{PrP}^{\mathrm{Sc}}$ accumulation. J Virol 72(2): 1153-9.

Ilc G, Giachin G, Jaremko M, Jaremko L, Benetti F, Plavec J, Zhukov I, Legname G (2010) NMR structure of the human prion protein with the pathological Q212P mutation reveals unique structural features. PLoS ONE 5(7): e11715.

Inouye H, Kirschner DA (1996) Refined fibril structures: the hydrophobic core in Alzheimer's amyloid beta-protein and prion as revealed by X-ray diffraction. Ciba Found Symp 199: 2235; discussion 35-9.

Jeong BH, Jin HT, Choi EK, Carp RI, Kim YS (2012) Lack of association between 14-3-3 beta gene (YWHAB) polymorphisms and sporadic Creutzfeldt-Jakob disease (CJD). Mol Biol Rep 39(12): 10647-53.

Joszai V, Turi I, Kallay C, Pappalardo G, Di Natale G, Rizzarelli E, Sovago I (2012) Mixed metal copper(II)-nickel(II) and copper(II)-zinc(II) complexes of multihistidine peptide fragments of human prion protein. J Inorg Biochem 112: 17-24.

Julien O, Chatterjee S, Bjorndahl TC, Sweeting B, Acharya S, Semenchenko V, Chakrabartty A, Pai EF, Wishart DS, Sykes BD, Cashman NR (2011) Relative and regional stabilities of the hamster, mouse, rabbit, and bovine prion proteins toward urea unfolding assessed by nuclear magnetic resonance and circular dichroism spectroscopies. Biochemistry 50(35): 7536-45.

Julien O, Chatterjee S, Thiessen A, Graether SP, Sykes BD (2009) Differential stability of the bovine prion protein upon urea unfolding. Protein Sci 18(10): 2172-82.

Kanyo ZF, Pan KM, Williamson RA, Burton DR, Prusiner SB, Fletterick RJ, Cohen FE (1999) Antibody binding defines a structure for an epitope that participates in the $\operatorname{PrP}^{\mathrm{C}} \rightarrow \mathrm{PrP}^{\mathrm{Sc}}$ conformational change. J Mol Biol 293(4): 855-63.

Khan MQ, Sweeting B, Mulligan VK, Arslan PE, Cashman NR, Pai EF, Chakrabartty A (2010) Prion disease susceptibility is affected by beta-structure folding propensity and local sidechain interactions in PrP. Proc Natl Acad Sci USA 107(46): 19808-13.

Knaus KJ, Morillas M, Swietnicki W, Malone M, Surewicz WK, Yee VC (2001) Crystal structure of the human prion protein reveals a mechanism for oligomerization. Nat Struct Biol 8(9): $770-4$.

Kourie JI, Kenna BL, Tew D, Jobling MF, Curtain CC, Masters CL, Barnham KJ, Cappai R (2003) Copper modulation of ion channels of PrP[106-126] mutant prion peptide fragments. J Membr Biol 193(1): 35-45.

Kuwata K, Matumoto T, Cheng H, Nagayama K, James TL, Roder H (2003) NMR-detected hydrogen exchange and molecular dynamics simulations provide structural insight into fibril formation of prion protein fragment 106-126. Proc Natl Acad Sci USA 100(25): 14790-5.

Kuznetsov IB, Rackovsky S (2004) Comparative computational analysis of prion proteins reveals two fragments with unusual structural properties and a pattern of increase in hydrophobicity associated with disease-promoting mutations. Protein Sci 13(12): 3230-44.

Lange A, Gattin Z, Van Melckebeke H, Wasmer C, Soragni A, van Gunsteren WF, Meier BH (2009) A combined solid-state NMR and MD characterization of the stability and dynamics of the HET-s(218-289) prion in its amyloid conformation. Chembiochem 10(10): 1657-65. 
Lau A, Mays CE, Genovesi S, Westaway D (2012) RGG repeats of PrP-like Shadoo protein bind nucleic acids. Biochemistry 51(45): 9029-31.

Laws DD, Bitter HM, Liu K, Ball HL, Kaneko K, Wille H, Cohen FE, Prusiner SB, Pines A, Wemmer DE (2001) Solid-state NMR studies of the secondary structure of a mutant prion protein fragment of 55 residues that induces neurodegeneration. Proc Natl Acad Sci USA 98(20): 11686-90.

Lee SW, Mou Y, Lin SY, Chou FC, Tseng WH, Chen CH, Lu CY, Yu SS, Chan JC (2008) Steric zipper of the amyloid fibrils formed by residues 109-122 of the Syrian hamster prion protein. J Mol Biol 378(5): 1142-54.

Lee DC, Sakudo A, Kim CK, Nishimura T, Saeki K, Matsumoto Y, Yokoyama T, Chen SG, Itohara S, Onodera T (2006) Fusion of Doppel to octapeptide repeat and N-terminal half of hydrophobic region of prion protein confers resistance to serum deprivation. Microbiol Immunol 50(3): 203-9.

Liang J, Kong Q (2012) $\alpha$-Cleavage of cellular prion protein. Prion 6(5): 453-60.

Liao YC, Tokes Z, Lim E, Lackey A, Woo CH, Button JD, Clawson GA (1987) Cloning of rat "prion-related protein" cDNA. Lab Invest 57(4): 370-4.

Liu H, Farr-Jones S, Ulyanov NB, Llinas M, Marqusee S, Groth D, Cohen FE, Prusiner SB, James TL (1999) Solution structure of Syrian hamster prion protein $\mathrm{rPrP}(90-231)$. Biochemistry $38(17): 5362-77$.

Lutz J, Brabeck C, Niemann HH, Kloz U, Korth C, Lingappa VR, Brkle A (2010) Microdeletions within the hydrophobic core region of cellular prion protein alter its topology and metabolism. Biochem Biophys Res Commun 393(3): 439-44.

Margittai M, Langen R (2008) Fibrils with parallel in-register structure constitute a major class of amyloid fibrils: molecular insights from electron paramagnetic resonance spectroscopy. Q Rev Biophys 41(3-4): 265-97.

Mays CE, Coomaraswamy J, Watts JC, Yang J, Ko KW, Strome B, Mercer RC, Wohlgemuth SL, Schmitt-Ulms G, Westaway D (2014) Endoproteolytic processing of the mammalian prion glycoprotein family. FEBS J 281(3): 862-76.

Moore RA, Vorberg I, Priola SA (2005) Species barriers in prion diseases-brief review. Arch Virol Suppl (19): 187-202.

Muramoto T, Kitamoto T, Tateishi J, Goto I (1992) Successful transmission of Creutzfeldt-Jakob disease from human to mouse verified by prion protein accumulation in mouse brains. Brain Res 599(2): 309-16.

Oliveira-Martins JB, Yusa S, Calella AM, Bridel C, Baumann F, Dametto P, Aguzzi A (2010) Unexpected tolerance of alpha-cleavage of the prion protein to sequence variations. PLoS One 5(2): e9107.

Ott CM, Akhavan A, Lingappa VR (2007) Specific features of the prion protein transmembrane domain regulate nascent chain orientation. J Biol Chem 282(15): 11163-71.

Ott CM, Lingappa VR (2004) Signal sequences influence membrane integration of the prion protein. Biochemistry 43(38): 11973-82.

Owen JP, Maddison BC, Whitelam GC, Gough KC (2007) Use of thermolysin in the diagnosis of prion diseases. Mol Biotechnol 35(2): 161-70. 
Patel A, Vasiljevic S, Jones IM (2013) Unique structural properties associated with mouse prion $\triangle 105-125$ protein. Prion 7(3): 235-43.

Peretz D, Williamson RA, Kaneko K, Vergara J, Leclerc E, Schmitt-Ulms G, Mehlhorn IR, Legname G, Wormald MR, Rudd PM, Dwek RA, Burton DR, Prusiner SB (2001) Antibodies inhibit prion propagation and clear cell cultures of prion infectivity. Nature 412(6848): 73943.

Pimenta J, Viegas A, Sardinha J, Martins IC, Cabrita EJ, Fontes CM, Prates JA, Pereira RM (2013) NMR solution structure and SRP54M predicted interaction of the N-terminal sequence (1-30) of the ovine Doppel protein. Peptides 49C: 32-40.

Premzl M, Sangiorgio L, Strumbo B, Marshall Graves JA, Simonic T, Gready JE (2003) Shadoo, a new protein highly conserved from fish to mammals and with similarity to prion protein. Gene 314: 89-102.

Priola SA, Chesebro B (1995) A single hamster PrP amino acid blocks conversion to proteaseresistant PrP in scrapie-infected mouse neuroblastoma cells. J Virol 69(12): 7754-8.

Ragg E, Tagliavini F, Malesani P, Monticelli L, Bugiani O, Forloni G, Salmona M (1999) Determination of solution conformations of PrP106-126, a neurotoxic fragment of prion protein, by ${ }^{1}$ H NMR and restrained molecular dynamics. Eur J Biochem 266(3): 1192-201.

Saez-Cirion A, Nieva JL, Gallaher WR (2003) The hydrophobic internal region of bovine prion protein shares structural and functional properties with HIV type 1 fusion peptide. AIDS Res Hum Retroviruses 19(11): 969-78.

Sakudo A, Lee DC, Li S, Nakamura T, Matsumoto Y, Saeki K, Itohara S, Ikuta K, Onodera T (2005a) PrP cooperates with STI1 to regulate SOD activity in PrP-deficient neuronal cell line. Biochem Biophys Res Commun 328(1): 14-9.

Sakudo A, Lee DC, Nishimura T, Li S, Tsuji S, Nakamura T, Matsumoto Y, Saeki K, Itohara S, Ikuta K, Onodera T (2005b) Octapeptide repeat region and N-terminal half of hydrophobic region of prion protein $(\mathrm{PrP})$ mediate PrP-dependent activation of superoxide dismutase. Biochem Biophys Res Commun 326(3): 600-6.

Sakudo A, Nakamura I, Lee DC, Saeki K, Ikuta K, Onodera T (2007) Neurotoxic prion protein (PrP) fragment 106-126 requires the N-terminal half of the hydrophobic region of $\mathrm{PrP}$ in the PrP-deficient neuronal cell line. Protein Pept Lett 14(1): 1-6.

Saupe SJ (2011) The [Het-s] prion of Podospora anserina and its role in heterokaryon incompatibility. Semin Cell Dev Biol 22(5): 460-8.

Sauv S, Buijs D, Gingras G, Aubin Y (2012) Interactions between the conserved hydrophobic region of the prion protein and dodecylphosphocholine micelles. J Biol Chem 287(3): 191522

Seabury CM, Derr JN (2003) Identification of a novel ovine PrP polymorphism and scrapieresistant genotypes for St. Croix White and a related composite breed. Cytogenet Genome Res 102(1-4):85-8.

Shi Q, Dong XP (2011) (Ctm)PrP and ER stress: a neurotoxic mechanism of some special PrP mutants. Prion 5(3): 123-5.

Smith CJ, Drake AF, Banfield BA, Bloomberg GB, Palmer MS, Clarke AR, Collinge J (1997) Conformational properties of the prion octa-repeat and hydrophobic sequences. FEBS Lett 405(3): 378-84. 
Stewart P, Shen C, Zhao D, Goldmann W (2009) Genetic analysis of the SPRN gene in ruminants reveals polymorphisms in the alanine-rich segment of shadoo protein. J Gen Virol 90(Pt 10): $2575-80$.

Supattapone S, MuramotoT, Legname G, Mehlhorn I, Cohen FE, DeArmond SJ, Prusiner SB, Scott MR (2001) Identification of two prion protein regions that modify scrapie incubation time. J Virol 75(3): 1408-13.

Suzuki T, Kurokawa T, Hashimoto H, Sugiyama M (2002) cDNA sequence and tissue expression of Fugu rubripes prion protein-like: a candidate for the teleost orthologue of tetrapod PrPs. Biochem Biophys Res Commun 294(4): 912-7.

Sweeting B, Brown E, Khan MQ, Chakrabartty A, Pai EF (2013) N-terminal helix-cap in a-helix 2 modulates -state misfolding in rabbit and hamster prion proteins. PLoS One 8(5): e63047.

Tcherkasskaya O, Sanders W, Chynwat V, Davidson EA, Orser CS (2003) The role of hydrophobic interactions in amyloidogenesis: example of prion-related polypeptides. J Biomol Struct Dyn 21(3): 353-65.

Tseng CY, Yu CP, Lee HC (2009) Integrity of H1 helix in prion protein revealed by molecular dynamic simulations to be especially vulnerable to changes in the relative orientation of $\mathrm{H} 1$ and its S1 flank. Eur Biophys J 38(5): 601-11.

Turi I, Kallay C, Szikszai D, Pappalardo G, Di Natale G, De Bona P, Rizzarelli E, Sovago I (2010) Nickel(II) complexes of the multihistidine peptide fragments of human prion protein. J Inorg Biochem 104(8): 885-91.

Valensin D, Gajda K, Gralka E, Valensin G, Kamysz W, Kozlowski H (2010) Copper binding to chicken and human prion protein amylodogenic regions: differences and similarities revealed by Ni2+ as a diamagnetic probe. J Inorg Biochem 104(1): 71-8.

Vilches S, Vergara C, Nicolas O, Sanclimens G, Merino S, Varon S, Acosta GA, Albericio F, Royo M, Del Rio JA, Gavin R (2013) Neurotoxicity of prion peptides mimicking the central domain of the cellular prion protein. PLoS One 8(8): e70881.

Viles JH, Donne D, Kroon G, Prusiner SB, Cohen FE, Dyson HJ, Wright PE (2001) Local structural plasticity of the prion protein. Analysis of NMR relaxation dynamics. Biochemistry 40(9): 2743-53.

Vorberg I, Groschup MH, Pfaff E, Priola SA (2003) Multiple amino acid residues within the rabbit prion protein inhibit formation of its abnormal isoform. JVirol 77(3): 2003-9.

Wang X, He L, Zhao C, Du W, Lin J (2013) Gold complexes inhibit the aggregation of prion neuropeptides. J Biol Inorg Chem 18(7): 767-78.

Wang F, Yin S, Wang X, Zha L, Sy MS, Ma J (2010) Role of the highly conserved middle region of prion protein (PrP) in PrP-lipid interaction. Biochemistry 49(37): 8169-76.

Wegner C, Romer A, Schmalzbauer R, Lorenz H, Windl O, Kretzschmar HA (2002) Mutant prion protein acquires resistance to protease in mouse neuroblastoma cells. J Gen Virol 83(Pt 5): $1237-45$.

Xu H, He X, Zheng H, Huang LJ, Hou F, Yu Z, de la Cruz MJ, Borkowski B, Zhang X, Chen ZJ, Jiang QX (2014) Structural basis for the prion-like MAVS filaments in antiviral innate immunity. Elife 3:e01489.

Zhang J (2014a) Recent research advances in the Glycine-xxx-Glycine motif of mammalian prion proteins. Biochem Pharmacol 3(1): e151. doi:10.4172/2167-0501.1000e151 
Zhang J (2014b) What does the prion amyloid fibril structure in AGAAAAGA look like? Biochem Pharmacol 3(2): e158. doi:10.4172/2167- 0501.1000e158

Zhang X, Zhou X, Ding T, Gan W, Yang L, Yin X, Zhao D (2012) Polymorphisms of SPRN (shadow of prion protein homology) in three breeds of sheep in China. Virus Genes 44(3): 548-50.

Zhang JP, Zhang YL (2013) Molecular dynamics studies on 3D structures of the hydrophobic region PrP(109-136), Acta Biochimica et Biophysica Sinica (Shanghai) 45(6): 509-19.

Zhao H, Liu LL, Du SH, Wang SQ, Zhang YP (2012) Comparative analysis of the Shadoo gene between cattle and buffalo reveals significant differences. PLoS One 7(10): e46601.

Zweckstetter M (2013) Conserved amyloid core structure of stop mutants of the human prion protein. Prion 7(3): 193-7. 

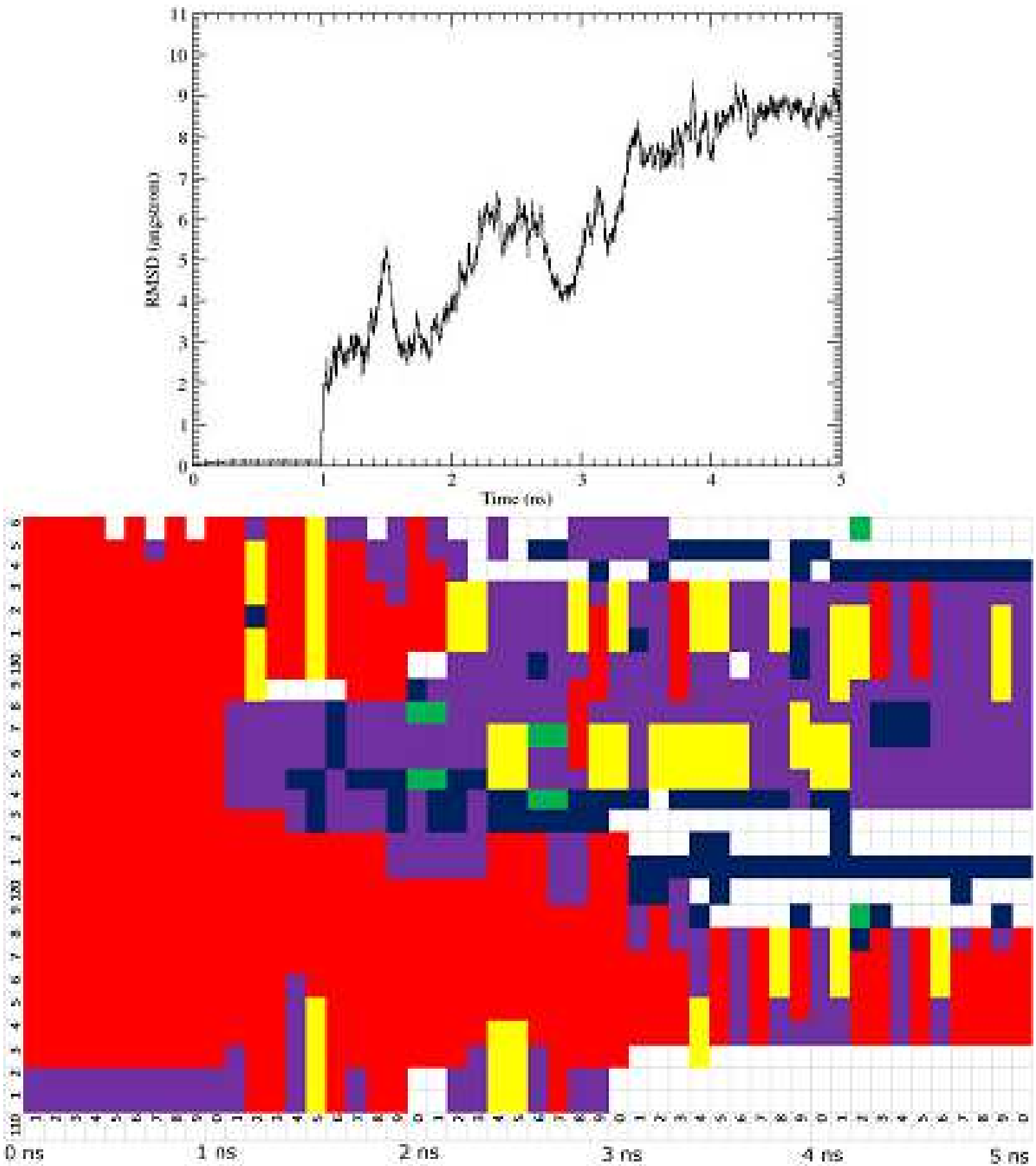

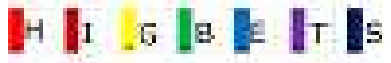
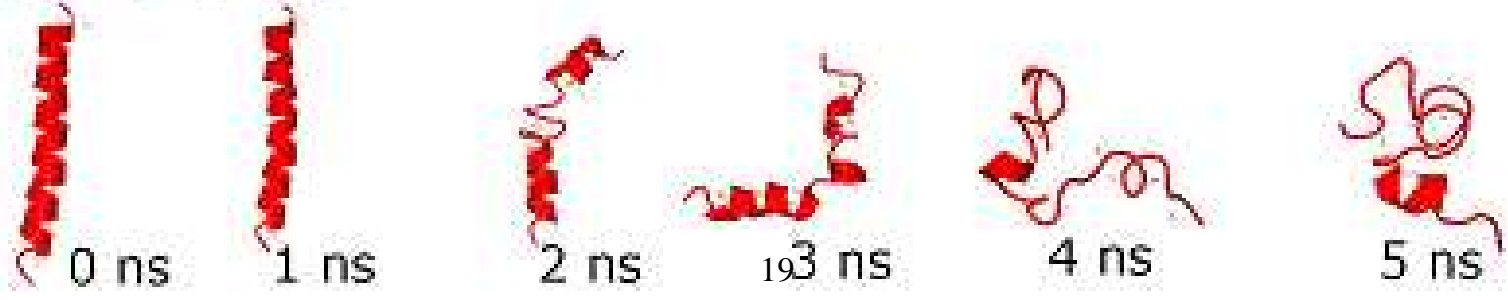

Figure 1: HuPrP(110-136) Variations of (A) the root-mean-squared deviations (RMSD), (B) the secondary structures, and (C) the respective snapshots at $0 \mathrm{~ns}, 1 \mathrm{~ns}, 2 \mathrm{~ns}, 3 \mathrm{~ns}, 4 \mathrm{~ns}$ and $5 \mathrm{~ns}$ of the MD simulations for $\operatorname{HuPrP}(110-136)$ 

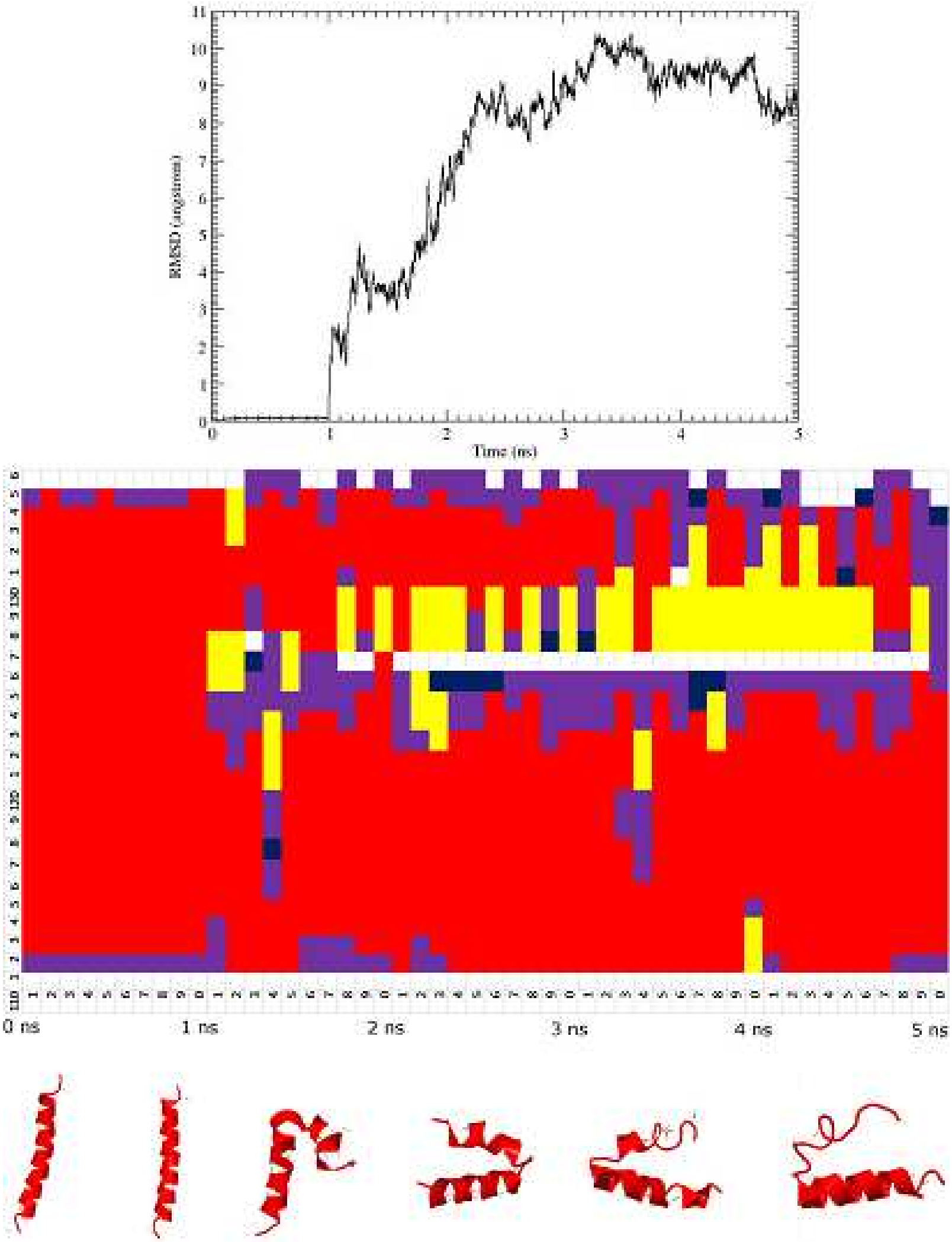

Figure 2: Mutant G114V Variations of (A) the rooffhean-squared deviations (RMSD), (B) the secondary structures, and (C) the respective snapshots at $0 \mathrm{~ns}, 1 \mathrm{~ns}, 2 \mathrm{~ns}, 3 \mathrm{~ns}, 4 \mathrm{~ns}$ and $5 \mathrm{~ns}$ of the MD simulations for mutant G114V. 

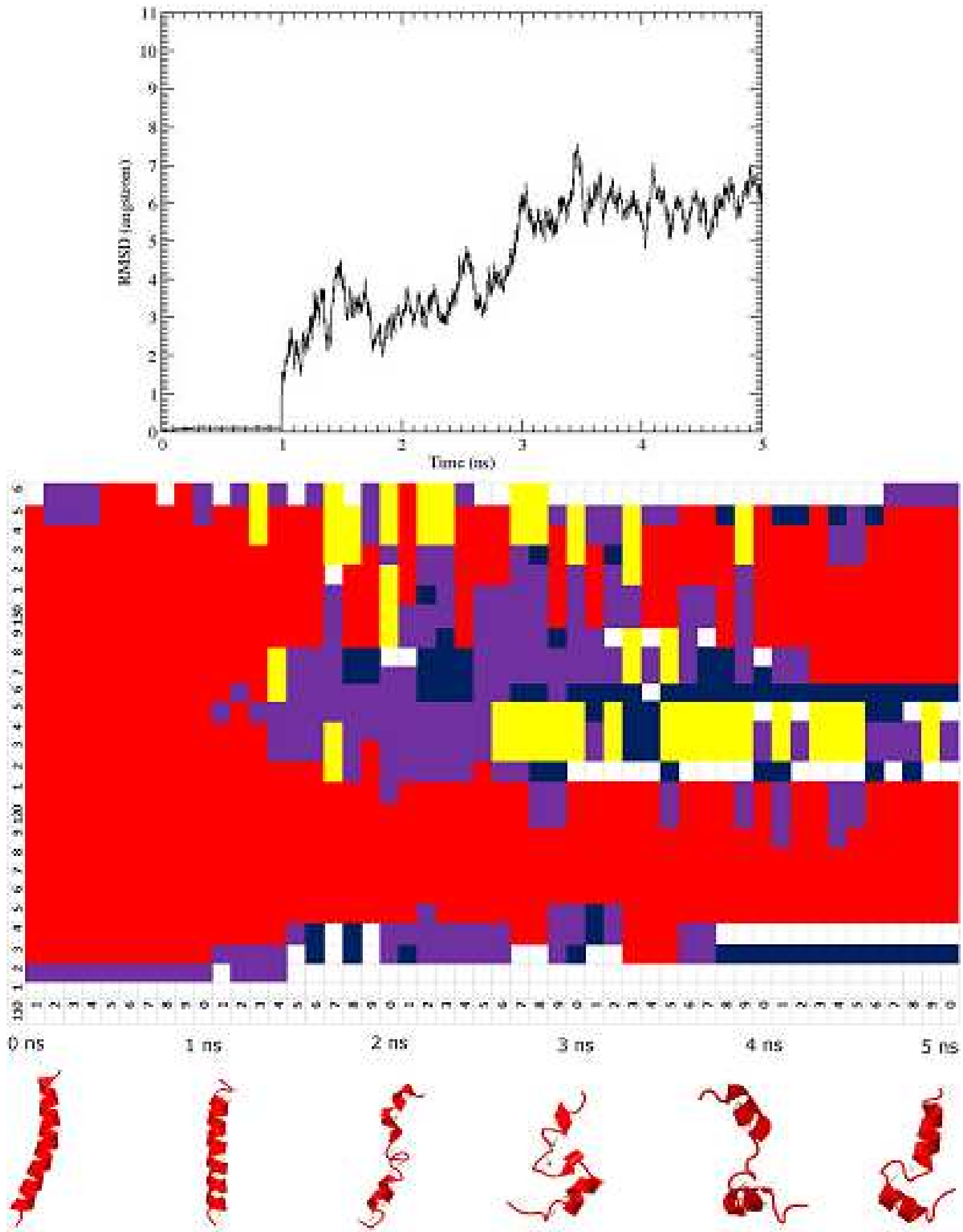

Figure 3: Mutant A117V Variations of (A) the root-mean-squared deviations (RMSD), (B) the secondary structures, and (C) the respective snapshots at $0 \mathrm{~ns}, 2 \mathrm{ys}, 2 \mathrm{~ns}, 3 \mathrm{~ns}, 4 \mathrm{~ns}$ and $5 \mathrm{~ns}$ of the MD simulations for mutant A117V. 

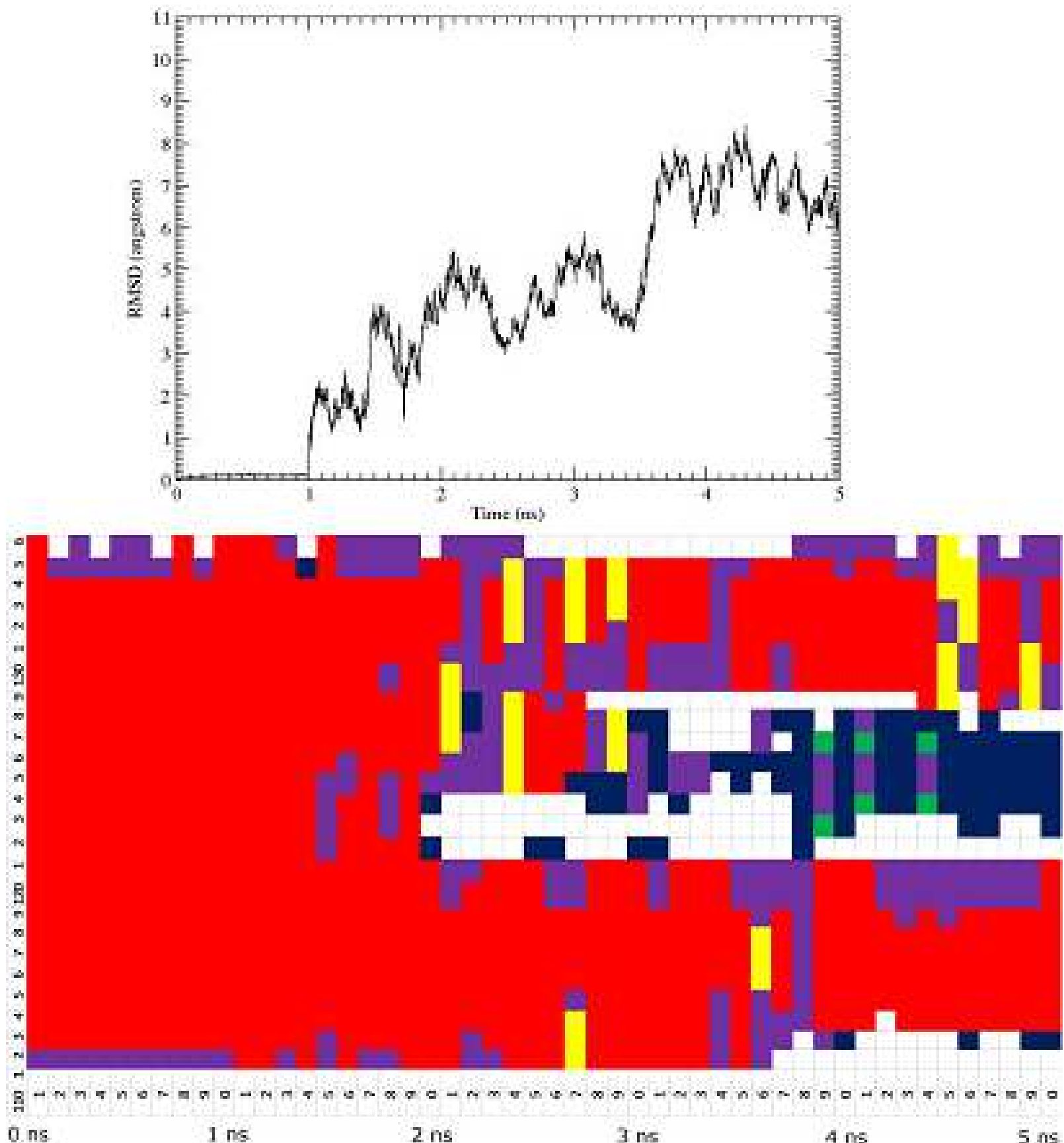

0 ns
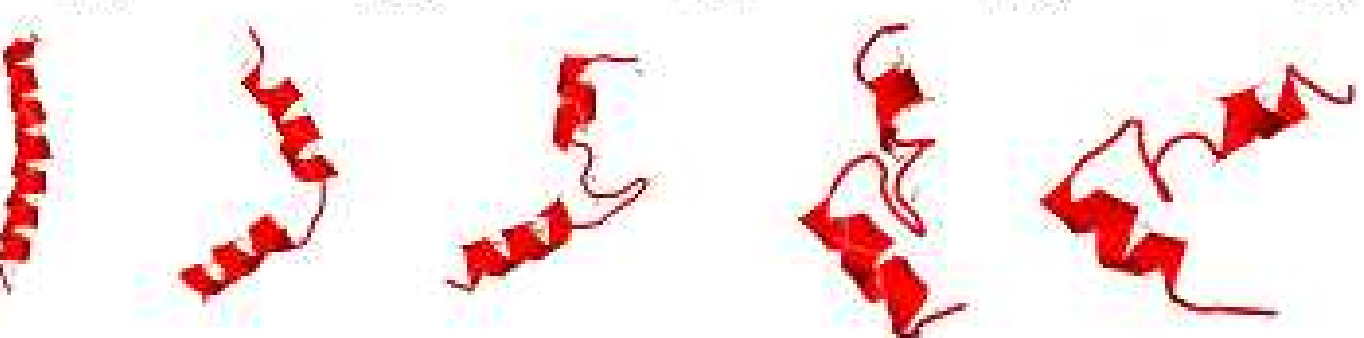

Figure 4: Mutant G119A Variations of (A) the root-mean-squared deviations (RMSD), (B) the secondary structures, and (C) the respective snapshots at $0 \mathrm{~ns}, 2 \mathrm{Rs}, 2 \mathrm{~ns}, 3 \mathrm{~ns}, 4 \mathrm{~ns}$ and $5 \mathrm{~ns}$ of the MD simulations for mutant G119A. 

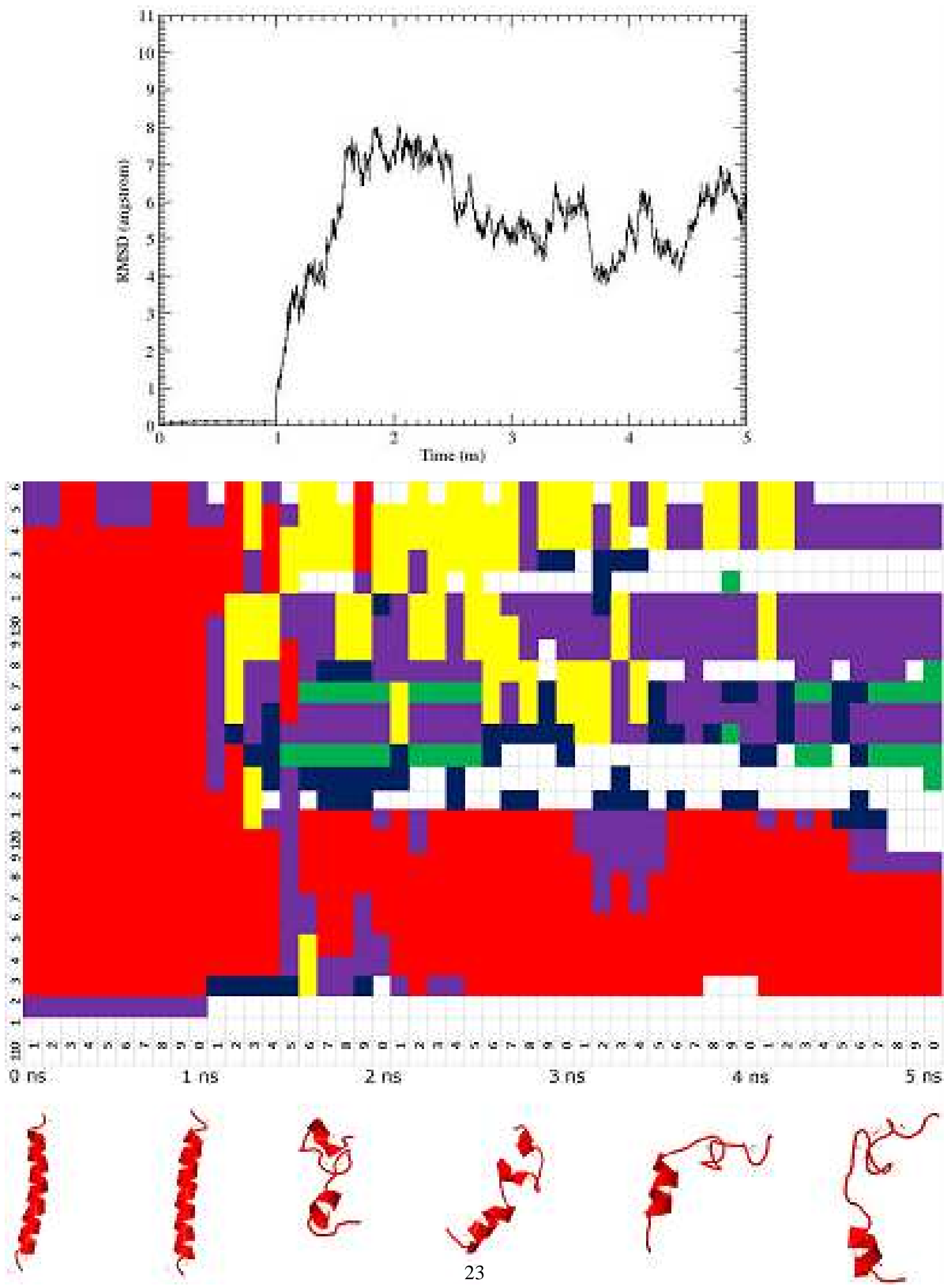

Figure 5: Mutant G119L Variations of (A) the root-mean-squared deviations (RMSD), (B) the secondary structures, and (C) the respective snapshots at $0 \mathrm{~ns}, 1 \mathrm{~ns}, 2 \mathrm{~ns}, 3 \mathrm{~ns}, 4 \mathrm{~ns}$ and $5 \mathrm{~ns}$ of the MD simulations for mutant G119L. 

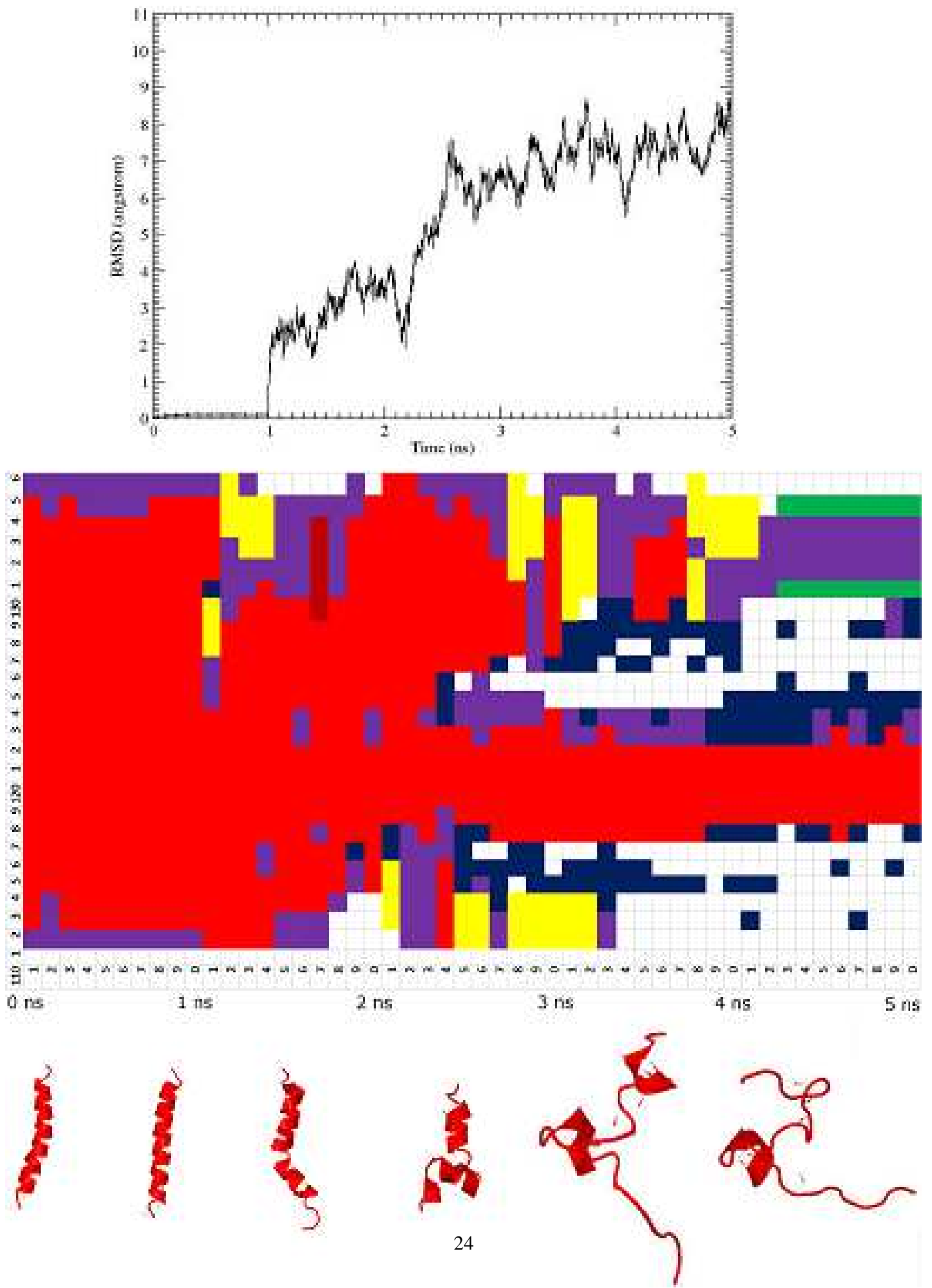

Figure 6: Mutant G119P Variations of (A) the root-mean-squared deviations (RMSD), (B) the secondary structures, and (C) the respective snapshots at $0 \mathrm{~ns}, 1 \mathrm{~ns}, 2 \mathrm{~ns}, 3 \mathrm{~ns}, 4 \mathrm{~ns}$ and $5 \mathrm{~ns}$ of the MD simulations for mutant G119P. 

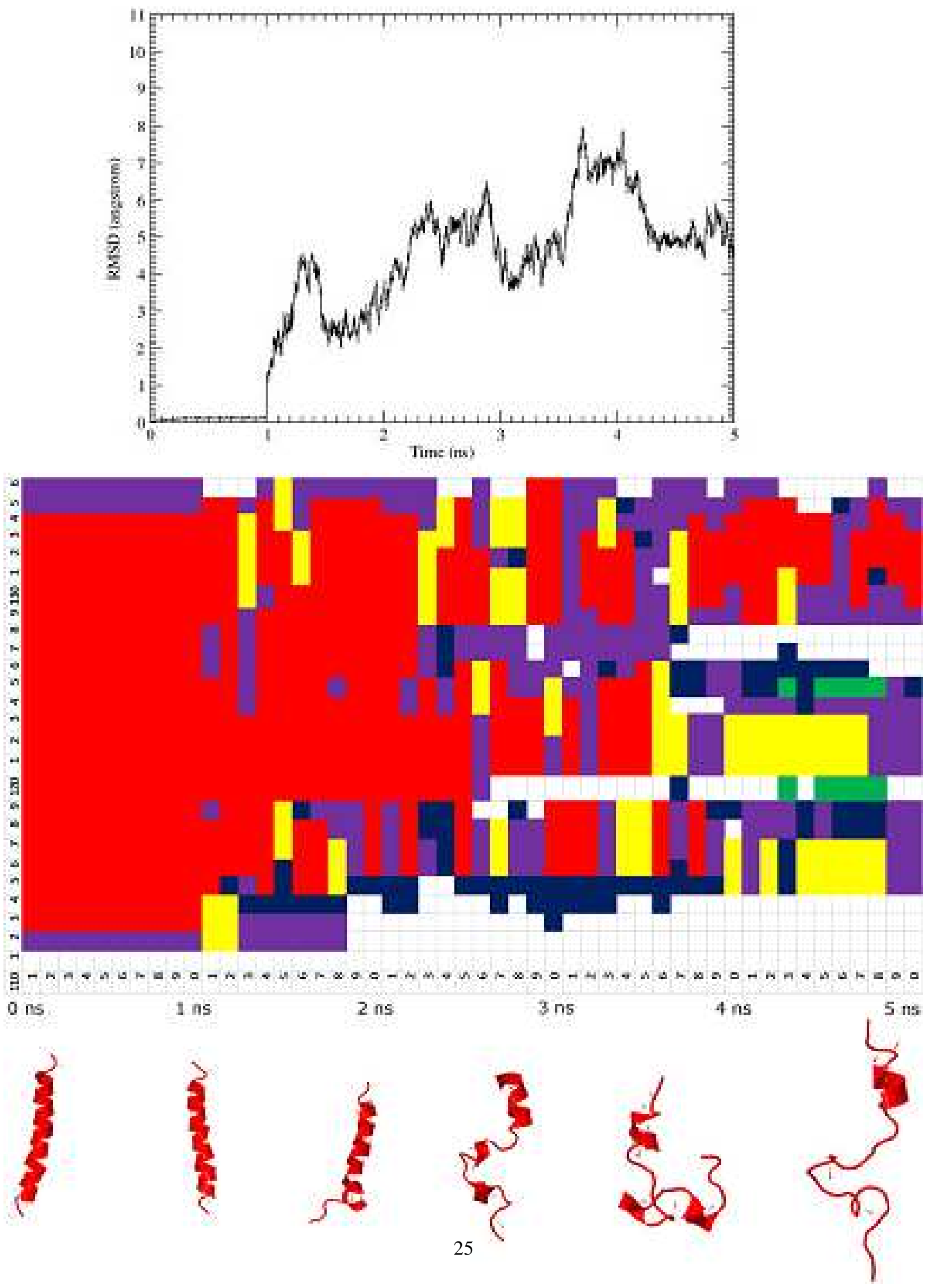

Figure 7: Mutant A120P Variations of (A) the root-mean-squared deviations (RMSD), (B) the secondary structures, and (C) the respective snapshots at $0 \mathrm{~ns}, 1 \mathrm{~ns}, 2 \mathrm{~ns}, 3 \mathrm{~ns}, 4 \mathrm{~ns}$ and $5 \mathrm{~ns}$ of the MD simulations for mutant A120P. 

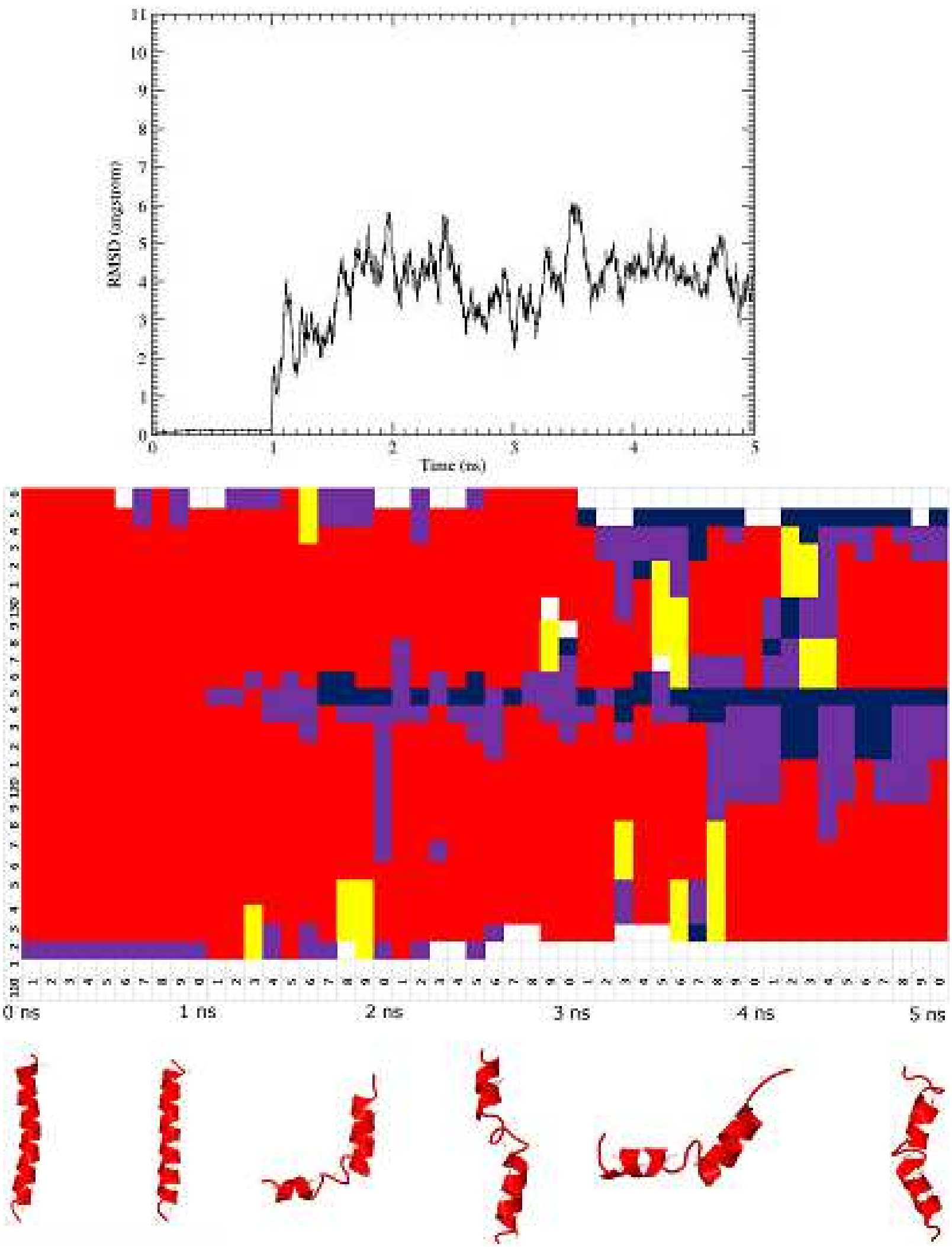

Figure 8: Mutant G123A Variations of (A) the rootmean-squared deviations (RMSD), (B) the secondary structures, and (C) the respective snapshots at $0 \mathrm{~ns}, 1 \mathrm{~ns}, 2 \mathrm{~ns}, 3 \mathrm{~ns}, 4 \mathrm{~ns}$ and $5 \mathrm{~ns}$ of the MD simulations for mutant G123A. 

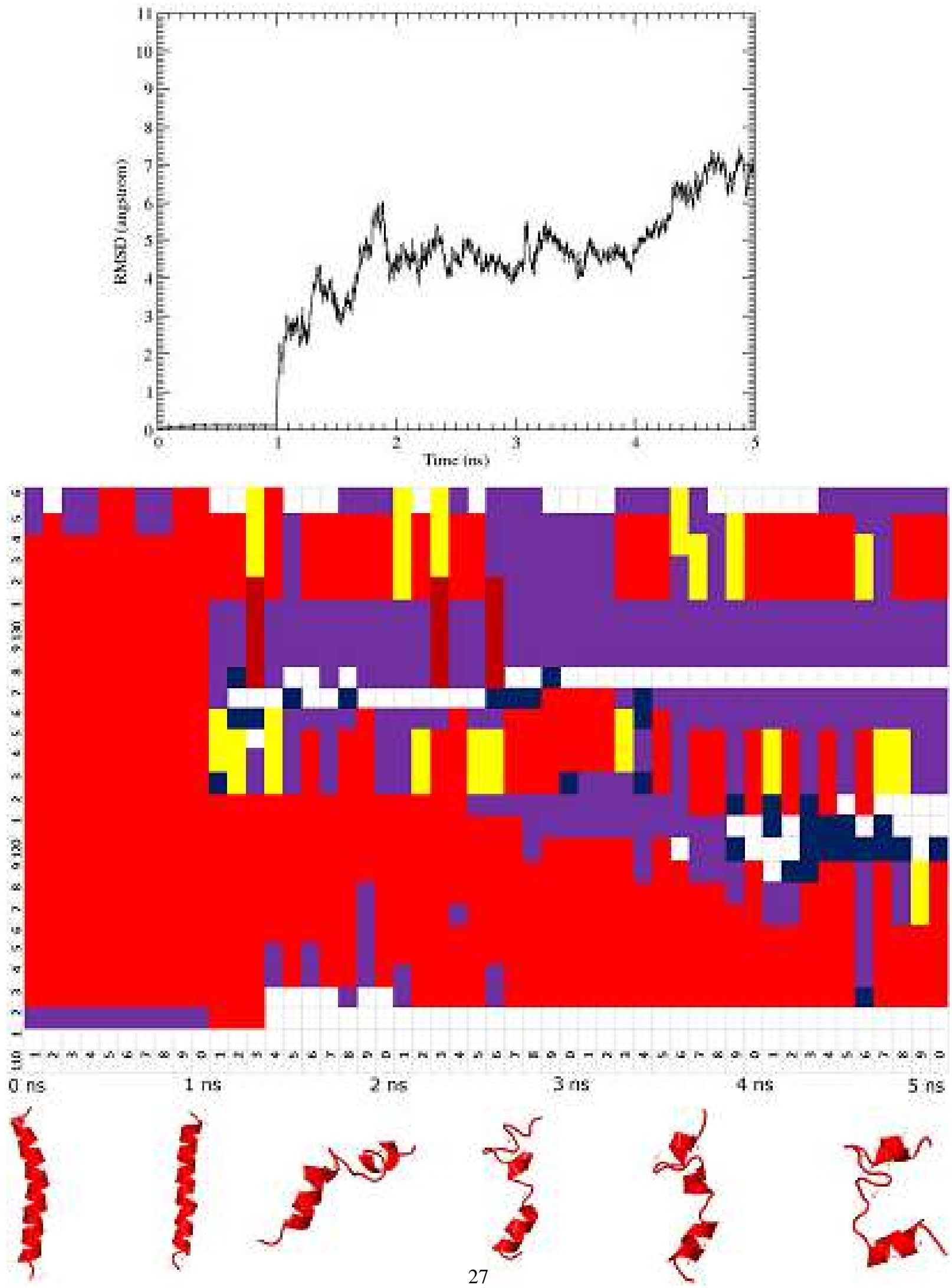

Figure 9: Mutant G123P Variations of (A) the root-mean-squared deviations (RMSD), (B) the secondary structures, and (C) the respective snapshots at $0 \mathrm{~ns}, 1 \mathrm{~ns}, 2 \mathrm{~ns}, 3 \mathrm{~ns}, 4 \mathrm{~ns}$ and $5 \mathrm{~ns}$ of the MD simulations for mutant G123P. 

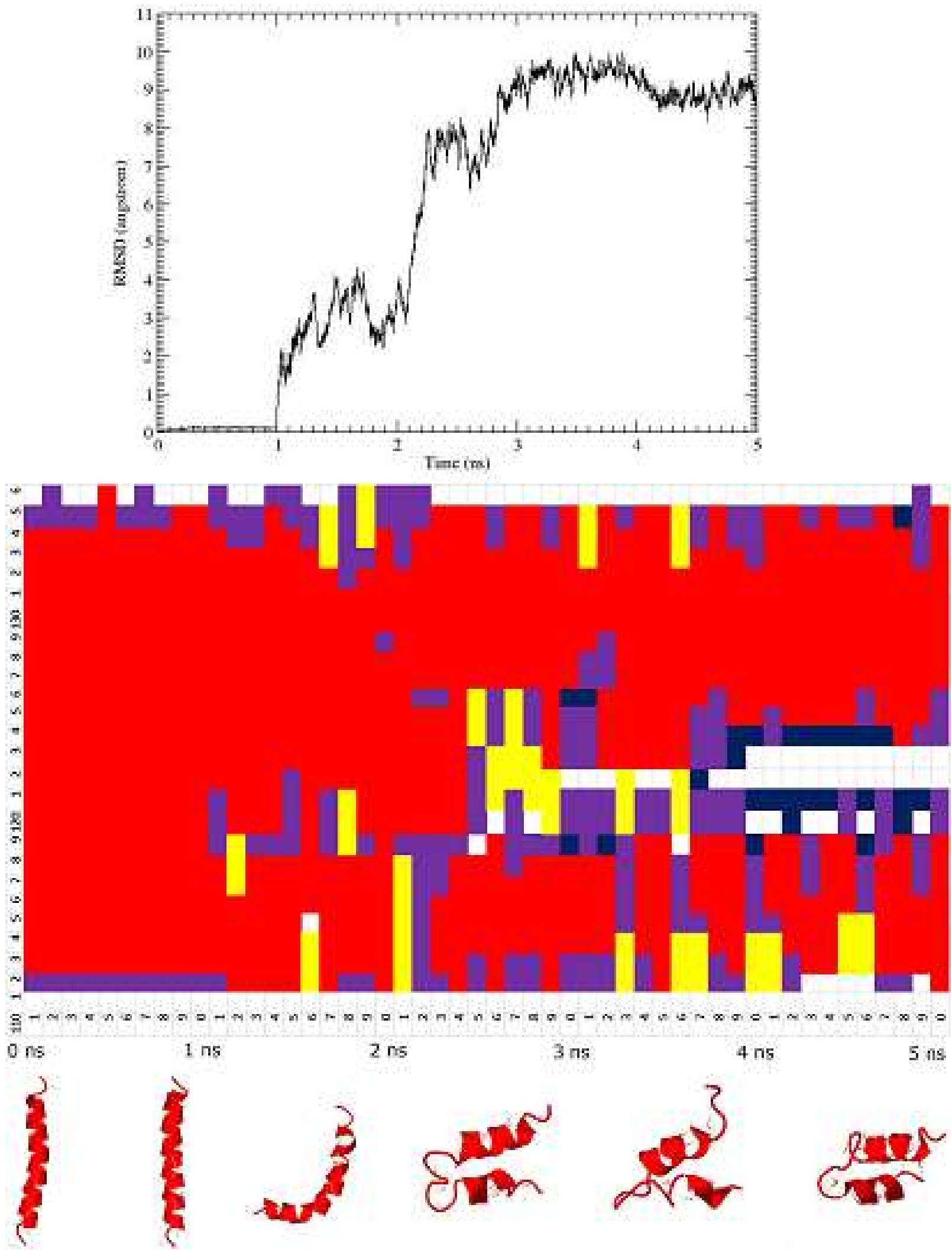

Figure 10: Mutant G124A Variations of (A) the root-mean-squared deviations (RMSD), (B) the secondary structures, and (C) the respective snapshots at $0 \mathrm{~ns}, 1 \mathrm{~ns}, 2 \mathrm{~ns}, 3 \mathrm{~ns}, 4 \mathrm{~ns}$ and $5 \mathrm{~ns}$ of the MD simulations for mutant G124A. 

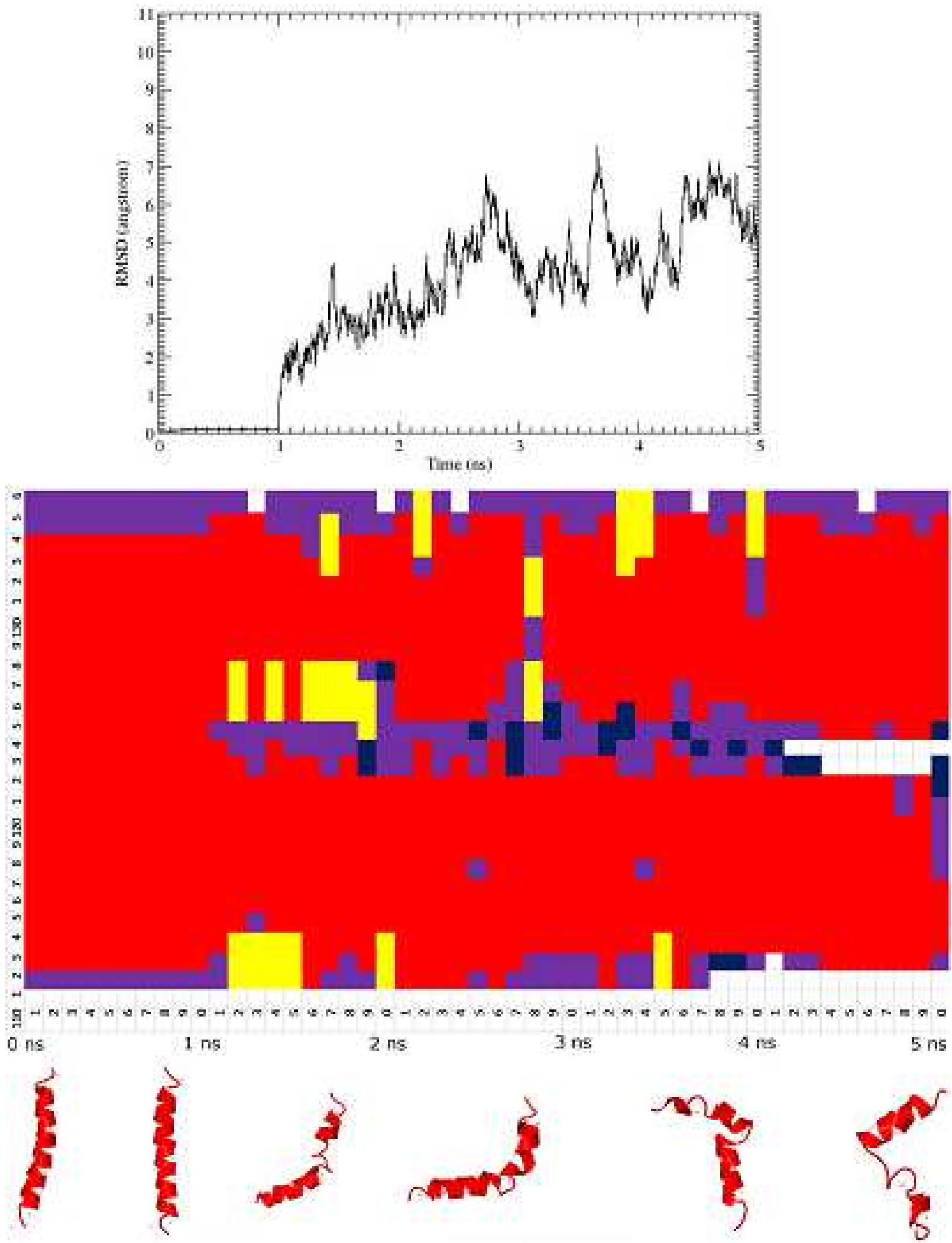

Figure 11: Mutant L125A Variations of (A) the rootonean-squared deviations (RMSD), (B) the secondary structures, and (C) the respective snapshots at $0 \mathrm{~ns}, 1 \mathrm{~ns}, 2 \mathrm{~ns}, 3 \mathrm{~ns}, 4 \mathrm{~ns}$ and $5 \mathrm{~ns}$ of the MD simulations for mutant L125A. 

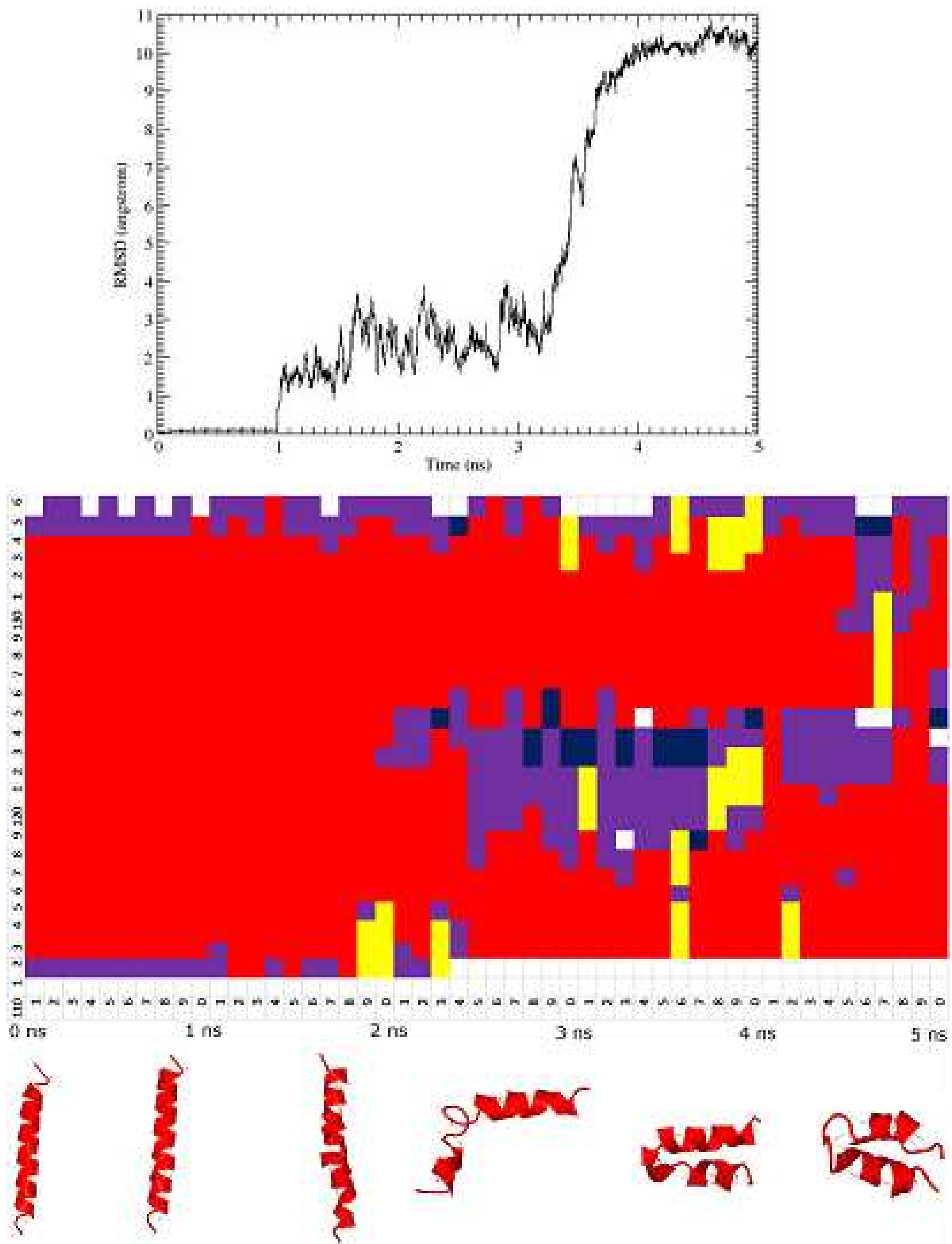

Figure 12: Mutant G126A Variations of (A) the roobonean-squared deviations (RMSD), (B) the secondary structures, and (C) the respective snapshots at $0 \mathrm{~ns}, 1 \mathrm{~ns}, 2 \mathrm{~ns}, 3 \mathrm{~ns}, 4 \mathrm{~ns}$ and $5 \mathrm{~ns}$ of the MD simulations for mutant G126A. 

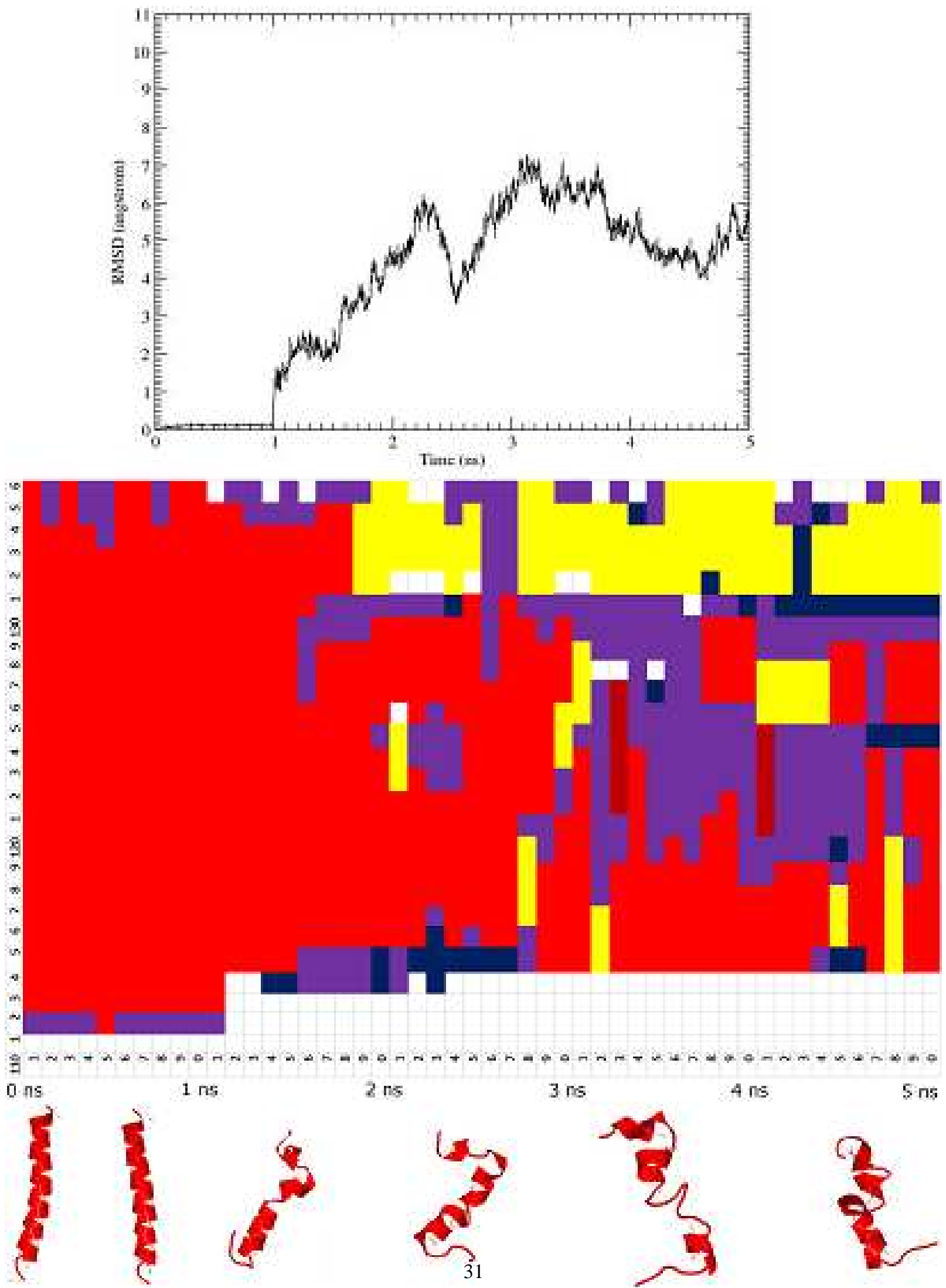

Figure 13: Mutant G127A Variations of (A) the root-mean-squared deviations (RMSD), (B) the secondary structures, and (C) the respective snapshots at $0 \mathrm{~ns}, 1 \mathrm{~ns}, 2 \mathrm{~ns}, 3 \mathrm{~ns}, 4 \mathrm{~ns}$ and $5 \mathrm{~ns}$ of the MD simulations for mutant G127A. 

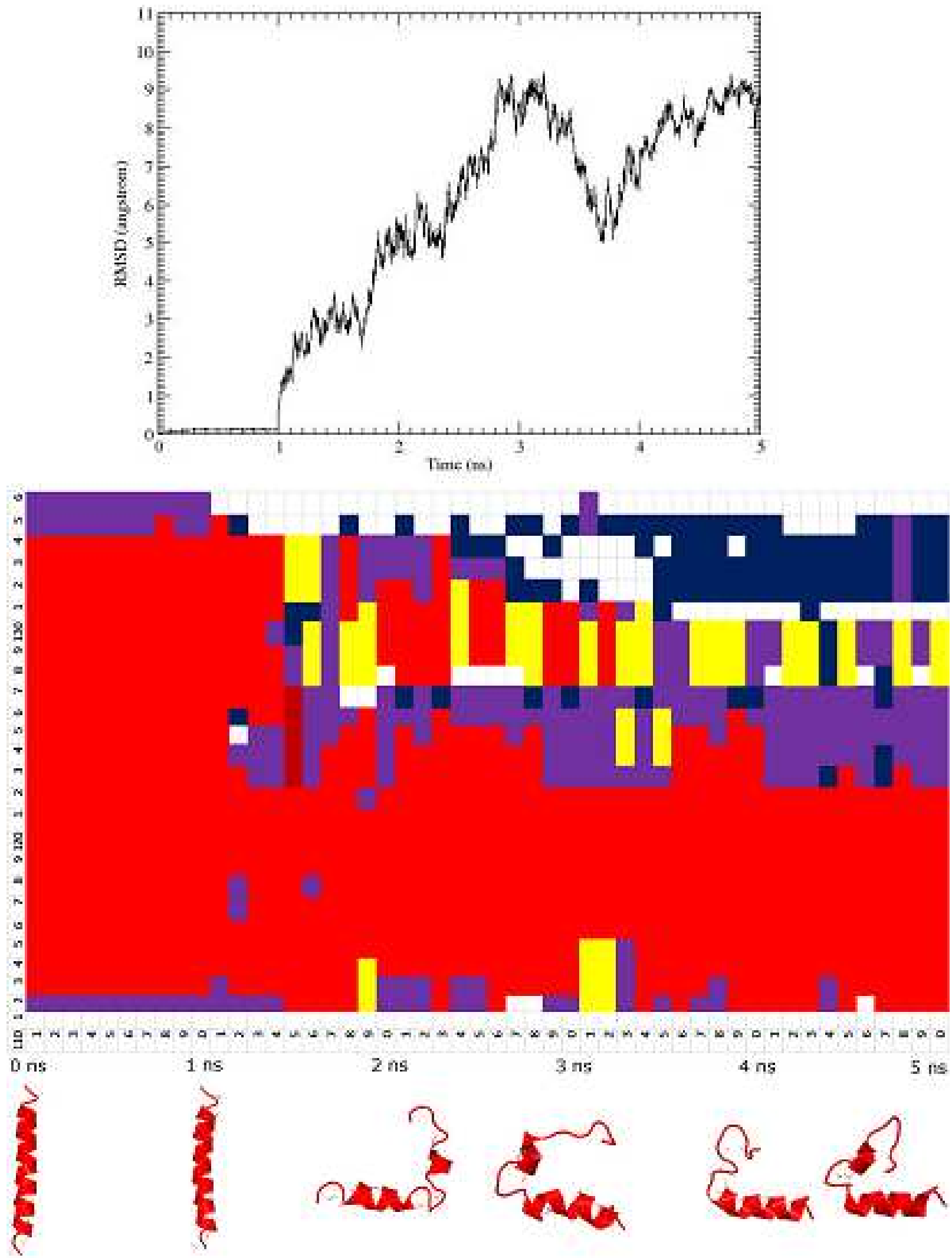

32

Figure 14: Mutant G127L Variations of (A) the root-mean-squared deviations (RMSD), (B) the secondary structures, and $(\mathrm{C})$ the respective snapshots at $0 \mathrm{~ns}, 1 \mathrm{~ns}, 2 \mathrm{~ns}, 3 \mathrm{~ns}, 4 \mathrm{~ns}$ and $5 \mathrm{~ns}$ of the MD simulations for mutant G127L. 

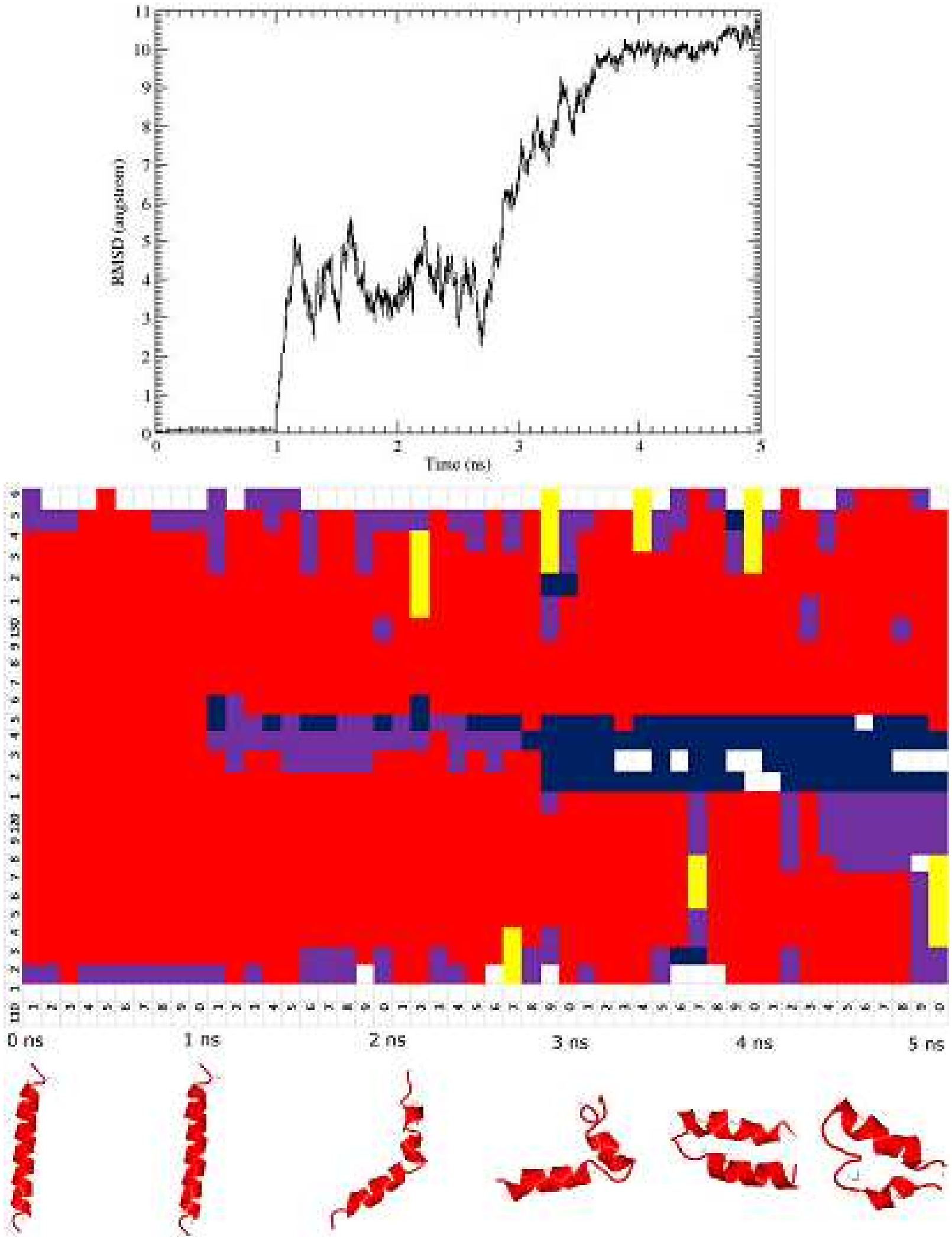

Figure 15: Mutant M129V Variations of (A) the root-mean-squared deviations (RMSD), (B) the secondary structures, and (C) the respective snapshots at $0 \mathrm{~ns}, 1 \mathrm{~ns}, 2 \mathrm{~ns}, 3 \mathrm{~ns}, 4 \mathrm{~ns}$ and $5 \mathrm{~ns}$ of the MD simulations for mutant M129V. 

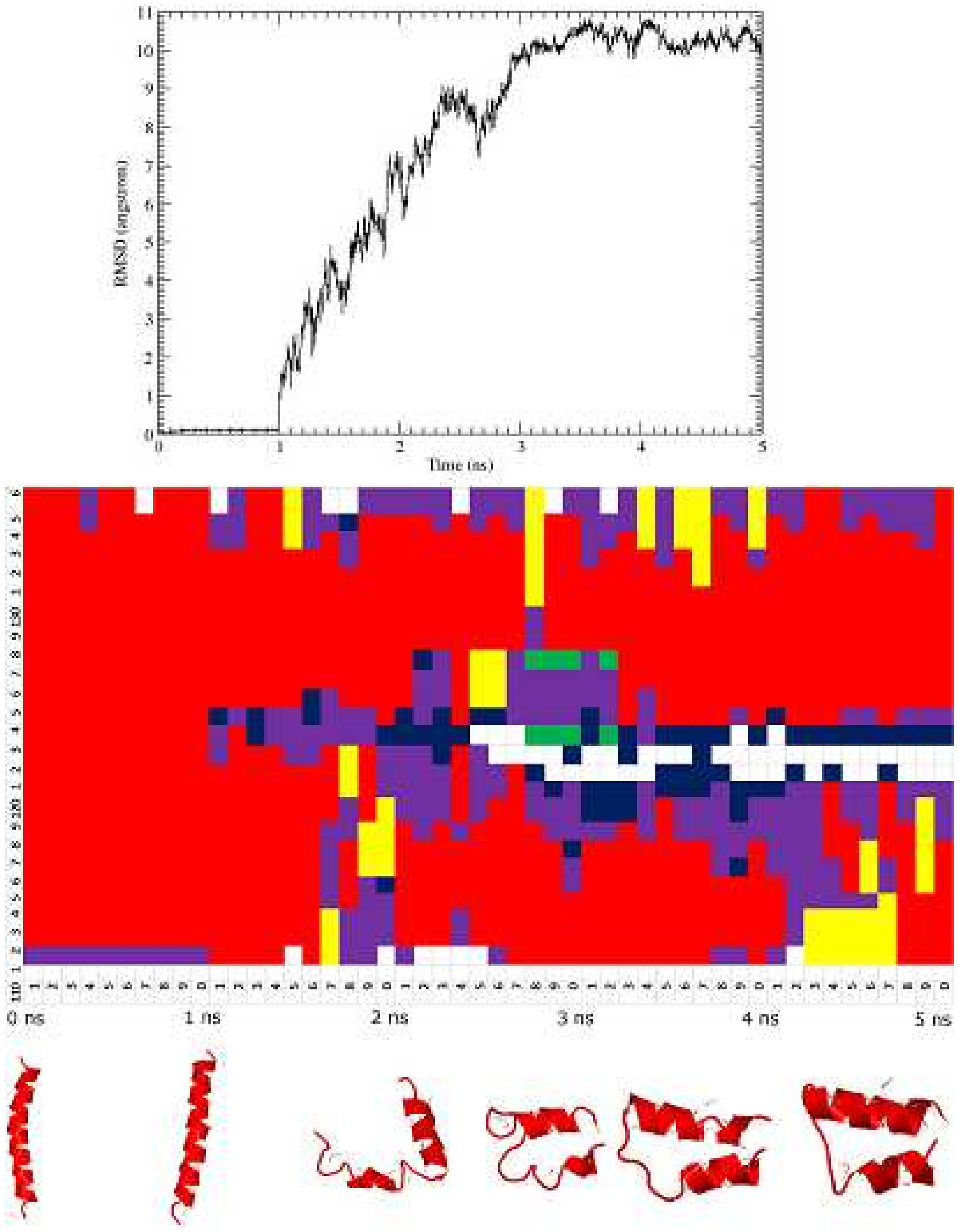

Figure 16: Mutant G131A Variations of (A) the root-mean-squared deviations (RMSD), (B) the secondary structures, and (C) the respective snapshots at $0 \mathrm{~ns}$, Buls, $2 \mathrm{~ns}, 3 \mathrm{~ns}, 4 \mathrm{~ns}$ and $5 \mathrm{~ns}$ of the MD simulations for mutant G131A. 

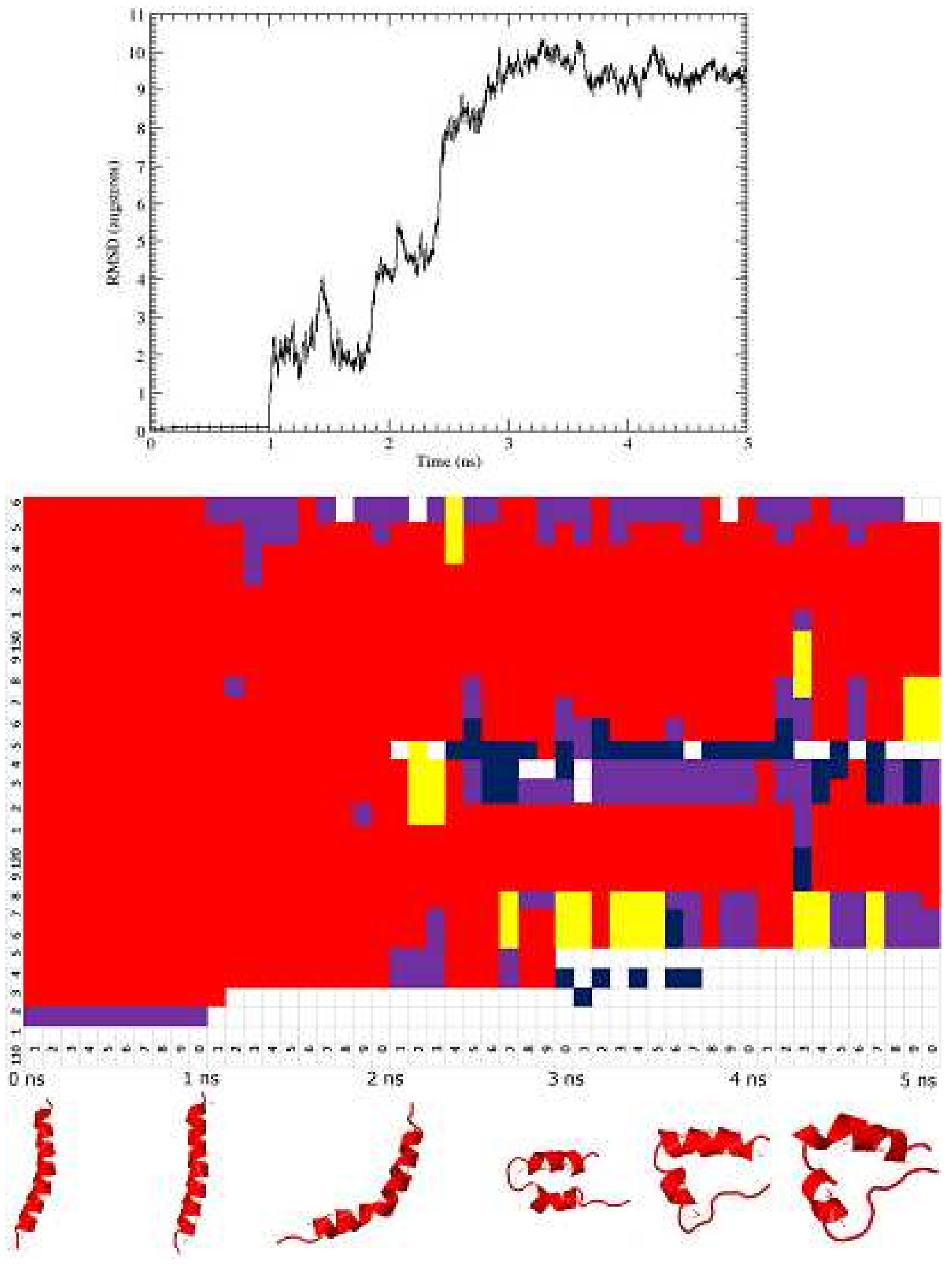

Figure 17: Mutant G131L Variations of (A) the root-mean-squared deviations (RMSD), (B) the secondary structures, and (C) the respective snapshots at $0 \mathrm{~ns}, 1 \mathrm{~ns}, 2 \mathrm{~ns}, 3 \mathrm{~ns}, 4 \mathrm{~ns}$ and $5 \mathrm{~ns}$ of the MD simulations for mutant G131L. 

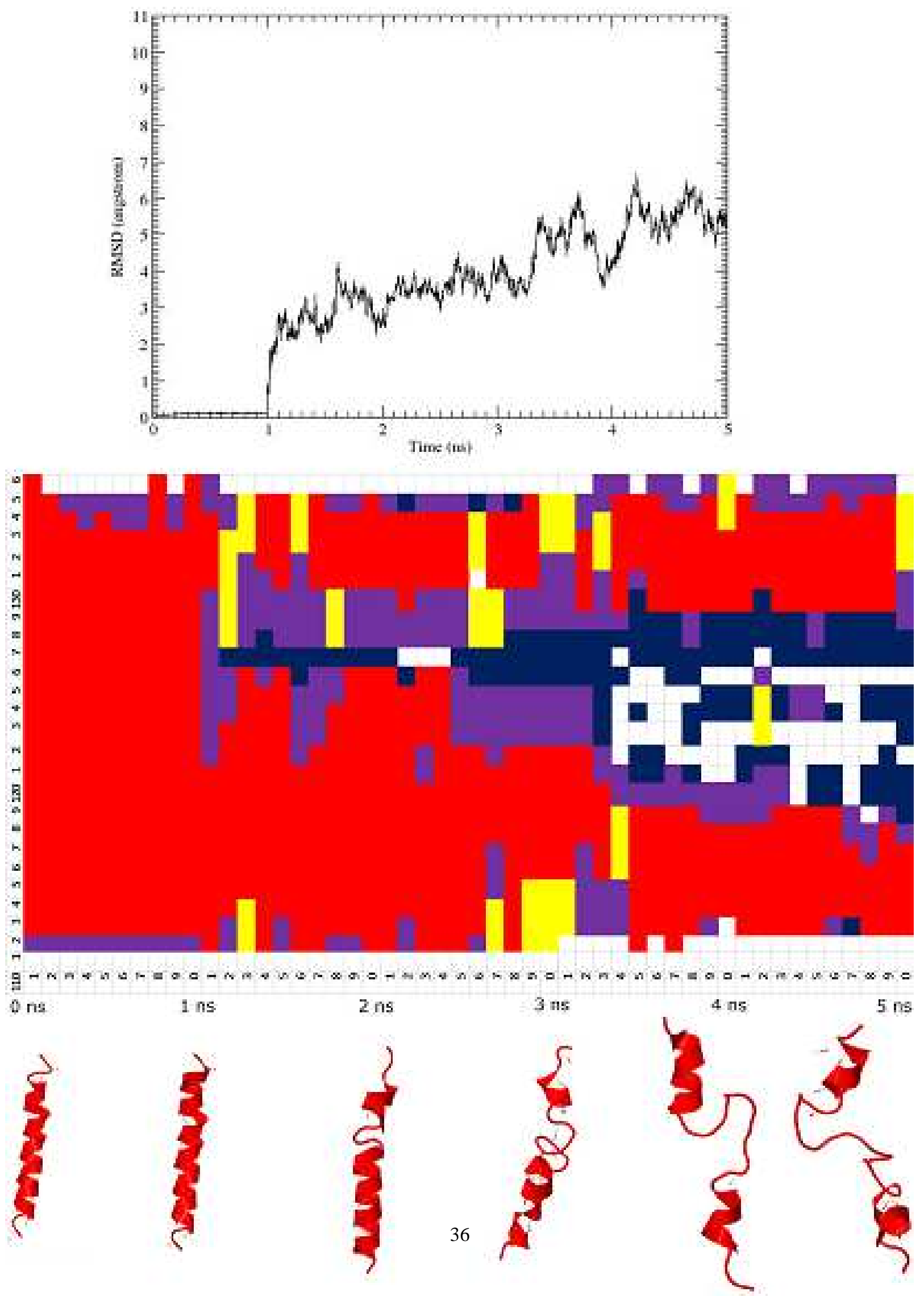

Figure 18: Mutant G131P Variations of (A) the root-mean-squared deviations (RMSD), (B) the secondary structures, and (C) the respective snapshots at $0 \mathrm{~ns}, 1 \mathrm{~ns}, 2 \mathrm{~ns}, 3 \mathrm{~ns}, 4 \mathrm{~ns}$ and $5 \mathrm{~ns}$ of the MD simulations for mutant G131P. 